\title{
Anotaciones acerca de la provisión de oficios capitales como acto jurídico y como acto de gobierno
}

\author{
Note on the Provision of Capital Offices as a Juridical Act \\ and as an Act of Government
}

\section{Fernando PUig SANAHUJa}

Profesor Asociado de Derecho de la Organización de la Iglesia

Pontificia Università della Santa Croce. Facoltà di Diritto Canonico. Roma

fpuig2@gmail.com

Resumen: El nombramiento de titulares de oficios capitales tiene importantes implicaciones sacramentales, un buen número de elementos jurídicoformales y una notable dimensión prudencial, pastoral y aun política. Estas facetas se relacionan con el derecho al buen gobierno que asiste a la comunidad de fieles. El análisis de las normas y de algunos elementos de la praxis aplicativa de estas dimensiones articulan el presente estudio. En primer lugar se afronta la dimensión jurídico-sacramental implicada en la provisión de oficios capitales. En segundo lugar se reflexiona sobre la comunión jerárquica como situación personal que es verificada en la provisión. En tercer lugar se estudian los aspectos de moderación del ministerio episcopal como sujeto colectivo que son tomados en consideración en la provisión del oficio capital.

Palabras clave: Obispos, Nombramiento, Gobierno eclesial.
Abstract: The appointment of holders of capital offices entails important sacramental implications, a number of legal-formal elements and significant prudential, pastoral and even political features. All these aspects are involved in the right of the ecclesial community to good governance. The purpose of this paper is to analyze the norms and some elements of their application regarding three dimensions of the act of provision. First, the legalsacramental dimension involved in the provision of episcopal offices is addressed. Second, the article focuses on hierarchical communion as a personal situation that is verified in such provision. Third, some of the moderating aspects of episcopal ministry relating to the provision of the capital office as such are taken into consideration.

Keywords: Bishops, Appointment, Church Governance. 


\section{INTRODUCCIÓN}

a reflexión jurídica sobre las normas positivas que disciplinan la provisión de los oficios capitales debe hacerse sin perder de vista la fundamental carga institucional que encierra esta concreción del episcopado ${ }^{1}$. En efecto la realidad jurídico-sacramental del ministerio episcopal gravita sobre las normas que orientan la acción que conduce a dotar de titular un oficio episcopal $^{2}$.

La variedad de dimensiones de la provisión pone de relieve que el nombramiento de obispos tiene importantes implicaciones sacramentales, un buen número de elementos jurídico-formales y una notable dimensión prudencial, pastoral y aun política, que encuentra su ajuste en el derecho al buen gobierno que asiste a la comunidad eclesial. La acción de provisión, configurada por las normas que la reglamentan, contiene exigencias de estos tres tipos, no siempre netamente separadas. El ejemplo más evidente es el constituido por los requisitos de idoneidad para la recepción del sacramento del orden en su grado supremo. Éstos son objeto de discernimiento en el contexto de la identificación de la persona que puede ser titular del oficio, hasta el punto que las consecuencias institucionales de la ordenación, especialmente la incorporación al colegio episcopal, no se realiza de modo aislado, sino en concomitancia con el nombramiento para ser obispo de una determinada sede. Este hecho no impide, como veremos, que existan criterios normativos sobre la ordenación episcopal.

Presupuesta la competencia para atribuir legítimamente la titularidad del oficio $^{3}$, las normas positivas que disciplinan la provisión de oficios capitales se reducen a unos procedimientos de selección e información (c. 377 CIC) y a

${ }^{1}$ Hemos estudiado las relaciones entre la dimensión institucional y personal del episcopado en el trabajo «La provvista dell'ufficio capitale come azione di governo relativa all'organizzazione istituzionale della Chiesa» (en fase de publicación).

${ }^{2}$ Lo expresa con precisión Errázuriz: «La elección directa de los apóstoles por parte de Jesucristo (cfr. Mt 10,1-4) indica con claridad la trascendencia fundacional de esa designación. La elección de sus sucesores es proporcionalmente decisiva para la vida de la Iglesia y se encuentra confiada a la misma Iglesia (...). El nombramiento de los obispos es una materia institucional de indudable importancia, no sólo particular, sino también universal. De ello se desprende que se refiere no sólo a la concreta comunidad eclesial y a las más cercanas, sino también a la conformación del Colegio de los Obispos y por lo tanto a la Iglesia universal» (C. J. ERrázuriz M., Corso fondamentale sul diritto nella Chiesa, vol. I, A. Giuffrè, Milano 2009, 442).

3 Sintéticamente esta competencia se formula así en el CIC: «El Sumo Pontífice nombra libremente a los Obispos, o confirma a los que han sido legítimamente elegidos» (c. $377 \$ 1$ ); «El juicio definitivo sobre la idoneidad del candidato corresponde a la Sede Apostólica» (c. 378 \$2). 
unos requisitos relativos a la persona para que pueda ser nombrada (c. 378 CIC). En este trabajo nos centramos en los requisitos relativos a la persona ${ }^{4}$.

En las normas citadas se plasman los cauces institucionales inherentes al ministerio episcopal tendentes a darle su consistencia personal. Su inserción sistemática en un artículo del Código titulado «De los obispos en general» (cc. 375-380 CIC) no debe llamar a engaño. Que trate de los obispos en general no quiere decir que trate de los obispos «en abstracto»; de hecho, se presupone en todo el artículo que se es obispo en relación al desarrollo de específicas funciones episcopales, en principio constitutivas de un oficio ${ }^{5}$. En efecto las referencias al ser pastor (c. $375 \$ 1 \mathrm{CIC}$ ), a las «cualidades que le hacen apto para ejercer el oficio de que se trata» (c. $378 \$ 1.1 \mathrm{CIC}$ ), y a la toma de posesión del oficio (cc. 379-380 CIC) evocan implícitamente la condición episcopal personal y las funciones que deberá desarrollar. Los procedimientos mismos del c. 377 CIC no persiguen otra cosa que favorecer la identificación de la persona más adecuada para un determinado oficio. De hecho, los cánones siguientes (el artículo siguiente del Código titulado «De los obispos diocesanos», cc. 381-402 CIC) no añaden ulteriores criterios específicos de idoneidad, aunque obviamente al describir las atribuciones y deberes del obispo diocesano se apunta al perfil funcional común de quienes son titulares del oficio de presidencia de una diócesis. De esta forma la acción de provisión se concibe como la aplicación de un conjunto de criterios y normas con un marcado contenido prudencial, que convergen terminativamente en la concesión de un título episcopal.

Esta concesión del título episcopal podrá incluir el mandato pontificio para la ordenación episcopal que es el factor jurídico-sacramental que incorpora al ordo episcopal y por ende, al colegio episcopal ${ }^{6}$. El hecho de que sea nor-

\footnotetext{
${ }^{4}$ En otro estudio nos ocupamos de los procedimientos: Le procedure per le nomine di vescovi: tra informazione e preferenza, Stato, Chiese e pluralismo confessionale 2 (2017) 1-35, donde afrontamos el contenido del c. 377 CIC y las normas contenidas en Consilium PRO PUblicis EcClesiae NegotiIs, Normae de promovendis ad Episcopatum in Ecclesia latina (25-III-1972), AAS 64 (1972) 386-391. Es interesante la integración que efectúa Tkhorovskyy de estos requisitos con el contenido de la Exhortación apostólica Pastores gregis (16-X-2003) y con el Directorio Apostolorum successores (22-II-2004); cfr. M. TKHOROvSKYY, Procedura per la nomina dei vescovi: evoluzione dal Codice del 1917 al Codice del 1983, Pontificia Università Gregoriana, Roma 2004, 192-195.

${ }^{5}$ La distinción entre requisitos para el estado episcopal («Bischofstand») y requisitos para el oficio episcopal («Bischofsamt»), tiene el mérito de la claridad pero no debe ser exagerada; en efecto, quien se sirve de esa distinción es consciente de que esos dos ámbitos no se pueden separar (cfr. G. BIER, Die Rechtsstellung des Diözesanbischofs nach dem Codex iuris canonici von 1983, Echter, Würzburg 2001, 87 y 92).

${ }^{6}$ Para distinguir el título episcopal del título de ordenación, cfr. V. DE PAOLIs, Nota sul titolo di consacrazione episcopale, Ius Ecclesiae 14 (2002) 59-79.
} 
mal que haya nombramientos para oficios capitales que no llevan consigo la ordenación episcopal porque quien ha sido nombrado era ya obispo, en nada desmiente que la provisión del oficio posee una trascendencia que debe seguir siendo considerada jurídico-sacramental. No sólo es sacramental la acción de ordenar legítimamente sino también el ministerio episcopal, tanto como depositario de la misión episcopal originaria, como desde el punto de vista de la composición personal histórica: quiénes son obispos y de qué se ocupan como tales obispos. Téngase en cuenta además que la provisión de oficios capitales (aun cuando no deba mediar mandato para una ordenación episcopal) supone una verificación de la comunión jerárquica efectiva, que es condición para una plena participación en el ministerio episcopal y en el colegio episcopal ${ }^{7}$. La inserción de la provisión del oficio capital en el contexto de la configuración personal tanto del ministerio episcopal como tal, como de su concreción en el oficio de que se trate en cada caso, ayuda a situar en su justo punto tanto los procedimientos como los requisitos establecidos en el derecho positivo.

Sin adentrarnos en las raíces doctrinales e históricas sobre el alcance de la proposición según la cual «el Sumo Pontífice nombra libremente a los Obispos» (c. $377 \$ 1$ CIC), consideramos que esta afirmación no sitúa el ejercicio de esa función al margen del derecho.

En un escrito publicado hace algunos años, Greshake cuestionaba el enunciado contenido en el canon, tanto sobre la base de la historia de los nombramientos episcopales como desde el punto de vista de la doctrina sobre el episcopado del Concilio Vaticano II. Manifestando a la vez su respeto por la figura del Romano Pontífice, el teólogo alemán reivindicaba que también en este caso (el nombramiento de obispos) la acción del Papa está vinculada a la estructura de la Iglesia ${ }^{8}$. Esta valoración nos permite señalar, como no podría ser de otro modo, que desde el punto de vista del derecho el enunciado del canon debe ser leído y aplicado, en efecto, en el contexto de los elementos constitutivos de la estructura de la Iglesia y principalmente de la estructura del

\footnotetext{
${ }^{7}$ Sobre la base de la comprensión de la provisión de oficios episcopales como una institucionalización de los cauces de atribución de funciones públicas como es denominado por Hervada a nivel constitucional (cfr. J. Hervada, Elementos de derecho constitucional canónico, Eunsa, Pamplona 2001, 184-187), hemos desarrollado esa comprensión a la vez sacramental y jurídica, institucional y personal del ministerio en el trabajo «La provvista dell'ufficio capitale come azione di governo relativa all'organizzazione istituzionale della Chiesa» (en fase de publicación).

${ }^{8}$ Cfr. G. GRESHAKE, Bischofsernennungen im Lichte einer Theologie des kirchlichen Amtes und einer Communio-Ekklesiologie, en G. GRESHAKE (ed.), Zur Frage der Bischofsernennungen in der römischkatholischen Kirche, Schnell \& Steiner, München 1991, 127-128.
} 
episcopado. La afirmación acerca de la competencia del Papa en el sentido indicado (libere nominat) implica que el nombramiento de obispos debe realizarse respetando los derechos y las funciones de los demás sujetos a los que afecta el ejercicio de tal función, y en ausencia de toda forma de arbitrariedad y de constricción. Nos parece que no es otra la finalidad de los requisitos y de los procedimientos normativamente establecidos, y que sobre la base de estos criterios deben ser interpretados.

En relación a esta cuestión, Bier rechaza que la intervención de sujetos diferentes del Papa en el nombramiento de obispos se pueda denominar «designación» ${ }^{9}$. En su lugar afirma que la dicción precisa sería «colaboración en la comprobación de los requisitos» ${ }^{10}$ ya que se trata de un juicio que no vincula a quien nombra efectivamente al titular. La observación es pertinente; quien efectúa la atribución del título no comparte la competencia con quienes de un modo u otro coadyuvan en la fase preliminar, informativa y propositiva, y da pie para abundar en la cuestión.

En relación a la categoría general de la provisión del oficio, es tradicional distinguir tres fases: la designación de la persona, la asunción o concesión del título y la toma de posesión ${ }^{11}$. Dejando de lado la toma de posesión, que es relevante para el efecto despliegue de las funciones del oficio y puede tener importantes consecuencias jurídicas, pero influye poco en la acción que conduce al nombramiento en sí mismo considerado, la distinción es clara operativamente y desde el punto de vista cronológico. De todos modos, con la distinción no se niega que pueda haber derechos, facultades de intervención o al menos expectativas de intervención en la fase de designación, dejando incólu-

${ }^{9}$ Lo hace a propósito del uso de esta expresión («designation of bishops») para referirse a los procedimientos del c. 377 CIC, en T. J. GREEN, Particular Churches and their groupings (cc. 368-572), en T. J. Green - D. E. Heintschel - J. A. Coriden - Canon Law Society of America (eds.), The Code Of Canon Law: A Text And Commentary, G. Chapman-Paulist Press, LondonNew York 1985, 320-323.

10 Toma la formulación («Mitwirkung an der Eignungsfeststellung») de H. HeIMERL - H. PrEe, Kirchenrecht. Allgemeine Normen und Eherecht, Springer, Wien-New York 1983, 124.

11 Cfr. F. X. WERNZ - P. VIDAL, De personis (Ius canonicum, vol. II), Universitatis Gregorianae, Romae 1943, 243-244; J. I. ARRIETA, Diritto dell'organizzazione ecclesiastica, A. Giuffrè, Milano 1997, 171-174; L. SABbaRESE, «Provisión del oficio», en Diccionario general de derecho canónico, VI, Instituto Martín de Azpilcueta, Pamplona 2012, 621. En los tratados clásicos, en la distinción entre designación y concesión del título se ventila la diferencia entre la posición de quien ostenta un ius ad rem o un ius in re, es decir, se considera el problema desde la perspectiva del que ha sido nombrado. En el texto tratamos la cuestión más bien desde la perspectiva del alcance jurídico de la acción de quienes intervienen en los procedimientos y en definitiva de quien tiene la potestad para nombrar. 
me el derecho-función de quien libremente concede el título y, como indica la palabra, nombra al «titular». No nos referimos solamente a los casos en que hay derechos de presentación o se prevé una elección, sino específicamente a los relativos al nombramiento de obispos por libre colación ${ }^{12}$.

En este sentido aunque se puede defender que materialmente el contenido de la actividad desplegada en la preparación de la decisión de nombramiento puede ser calificada como una simple colaboración en la verificación de los requisitos, lo que deja intocada la acción del Papa destinada a la concesión del título (sólo el Papa «nombra»), no hace prescindibles esas actividades preparatorias si lo que se pretende es que el Papa nombre «prudentemente» es decir, ejercite su derecho-función efectivamente en favor del bien común de la Iglesia, universal y local. La perspectiva de gobierno que adoptamos en este trabajo relativiza el hecho que en la designación del titular no haya sujetos que ostenten un derecho a intervenir (como en algunas hipótesis de presentación o de elección) incluyendo en cambio los pasos que hacen de esa decisión (por libre colación: el Papa nombra «libremente») una medida prudente. Y esto lleva consigo que intervenga y que en cierto modo deba intervenir un cierto número de personas según unos criterios precisos, de modo efectivo y que, en fase decisoria, sea tenida seriamente en cuenta esa intervención.

Complementaria a la opinión de Greshake sería la de Rahner que algunos años antes, consideraba que no existía un «derecho divino» en relación al nombramiento de miembros del ministerio y que la única regla fundamental a este propósito era que la persona nombrada tenía que ser «adecuada» para ese ministerio ${ }^{13}$. Sin entrar en más valoraciones, nos parece que se puede afirmar que, cualesquiera que sean las personas que intervienen en los procedimientos, una persona adecuada para el concreto ministerio es la que se encuentra dentro de los límites señalados por el derecho (in primis, una idoneidad básica) y posee la previsible capacidad de conducir la comunidad en el mejor modo posible. En consecuencia, el derecho (y no sólo las normas positivas) excluye cualquier forma de arbitrariedad; tal exclusión puede ser atribuida tanto al derecho natural que orienta la acción de gobierno prudente

12 Cfr. J. MiÑambres, Concorso di diritti nelle provviste canoniche, Ius Ecclesiae 7 (1995) 115-130; La presentazione canonica. Collaborazione nella provvista degli uffici ecclesiastici, A. Giuffrè, Milano 2000.

${ }^{13}$ Cfr. K. RaHner, Strukturwandel der Kirche als Aufgabe und Chance, Herder, Freiburg im Breisgau-Basel-Wien 1972, 127-128. El autor decía no pronunciarse en ese pasaje acerca de la elección del Papa, y en cambio consideraba incluidos en la dicción «miembros del ministerio» no sólo a los obispos. 
como el derecho divino-positivo que sostiene la estructura del ministerio episcopal, uno de cuyos cauces institucionales es el conjunto del sistema de provisión de los oficios capitales ${ }^{14}$.

El presente estudio toma en consideración las exigencias jurídicas relativas a la validez y a la eficacia jurídicas de la provisión del oficio capital pero sin circunscribirse a ellas de modo exclusivo; en efecto, se integran en la perspectiva más amplia de la prudencia en la aplicación del derecho y las exigencias del buen gobierno ${ }^{15}$.

${ }^{14}$ No podemos convenir plenamente con esta afirmación de Bier: «En la mayor parte de los casos el Papa hace uso de su derecho de nombrar libremente (c. $377 \$ 1$ CIC). Sólo nombra a aquellos que según su opinión cumplen los requisitos canónicos. Por eso, como dominus canonum, puede desentenderse de algunos requisitos» (G. BIER, Die Rechtsstellung des Diözesanbischofs..., cit., 95). Este autor parece aislar la acción libre del Papa del procedimiento y aun de los requisitos. Nos parece precisamente que son los requisitos y el procedimiento, junto con todo el contexto de justicia en que se hallan, lo que favorece el obrar libre del Papa. En su caso, si considera que debe separarse de lo que se concluye de la valoración de los requisitos y procedimientos, para que su decisión sea ajustada a derecho tendrá que basarse en motivos por lo menos proporcionados. La expresión dominus canonum, no exenta de imprecisión desde una visión realista del derecho, no podría justificar una acción arbitraria. Más moderada es la expresión usada por Aymans y Mörsdorf: el Papa no se halla obligado a seguir las propuestas que recibe, pero para formarse su juicio ordinariamente sigue un procedimiento; cfr. W. AYMANS - K. MÖrSDORF, Kanonisches Recht. Lebrbuch aufgrund des Codex iuris canonici, vol. II, F. Schöningh, Paderborn (etc.) 1997, 330.

15 Aunque se deban considerar casi hipótesis de escuela, no se puede excluir como posible la nulidad de la ordenación episcopal o la invalidez de la provisión de un oficio episcopal por ausencia de requisitos materiales o formales necesarios. En ambos casos habría que afrontar el problema relacionado con el autor del acto (el Romano Pontífice). Una parte de los bienes que se protegen con los requisitos de la ordenación episcopal son equivalentes a aquellos que se piden en el caso de la ordenación sacerdotal o diaconal (la libertad, la intención recta, etc.; cfr. P. AMENTA, La dichiarazione di nullità dell'ordinazione sacerdotale, en GRUPPO ITALIANO DOCENTI DI DIRITTO CANONICO [ed.], Il diritto nel mistero della Chiesa [IV]. Prassi amministrativa e procedure speciali, Lateran University Press, Roma 2014, 349-364), aunque con los agravantes derivados de la condición de obispo, grado pleno del sacramento del orden. Implícitamente se puede considerar el caso de la dispensa de las obligaciones derivadas de la condición clerical del obispo, sobre la que no hay mucha información: «Para la concesión de la dispensa deben concurrir causas justas, más o menos graves según de trate de un obispo, de un presbítero o un diácono. Para los obispos, los abades y los moderadores supremos de la Institutos de vida consagrada y de las sociedades de vida apostólica clericales no se suele conceder la dispensa salvo en casos singulares. El procedimiento en ese caso se desarrolla en el nivel de consulta interdicasterial. En los últimos años se han hecho posibles más dispensas para esta tipología de clérigos teniendo en cuenta su dignidad. Los principios aplicativos son más o menos los mismos que los establecidos para los demás clérigos salvo algunas prerrogativas inherentes a sus oficios y responsabilidades eclesiales, y tomando en consideración el posible escándalo entre los fieles» (V. Mosca, La perdita della condizione giuridica clericale e il procedimento di dispensa dei suoi obblighi, en GRUPPO ITALIANO DOCENTI DI DIRITTO CANONICO [ed.], Il diritto nel mistero della Chiesa [IV]. Prassi amministrativa e procedure speciali, Lateran University Press, Roma 2014, 367). En otro contexto se trata de modo especial a los obispos (cfr. FRANCISCO, Rescriptum ex audientia ss.mi, De Collegio intra Congregationem pro Doctrina Fidei constituendo ad appellationes clericorum 
En este sentido, tales exigencias no recaen únicamente en el titular último de la competencia para nombrar obispos sino que, según grados distintos, afectan a todos los sujetos que intervienen en la valoración de los requisitos según los procedimientos previstos. Aunque las Normae de promovendis ad Episcopatum in Ecclesia latina de 1972 señalan a propósito de la investigación que conduce la Sede apostólica que quienes son interrogados den «un juicio prudente y meditado delante de Dios» (art. XII.1) no se trata exclusivamente de deberes morales. Además de la dimensión moral, aunque con matices según los casos, se trata de deberes jurídicos (de actividad, de colaboración, de veracidad, etc.) vinculados a una acción pública, como es la que conduce a la provisión de un oficio episcopal. Todos los que intervienen, pero especialmente los legados pontificios y los obispos a los que se refieren las normas procedimentales se hallan ligados a deberes formalmente institucionales derivados de su función eclesial, incluido el de secreto, enunciado de modo general en esas normas (art. XIV) ${ }^{16}$.

La delimitación del ámbito de estudio a la Iglesia católica latina nos lleva a fijar nuestra atención en la primera parte del canon, sin entrar en supuestos de confirmación de elección que -salvo en otros casos muy localizados (que a veces en realidad son formas de presentación) ${ }^{17}$ - se verifica principalmente en Iglesias sui iuris orientales ${ }^{18}$. En principio tomamos en consideración los oficios capitales cuya titularidad exige la condición episcopal.

circa graviora delicta consideranda, AAS 106 [2014] 885-886; art. 4: 4. «qualora il reo sia insignito della dignità episcopale, il suo ricorso sarà esaminato dalla Sessione Ordinaria»).

${ }^{16}$ Estudiamos el título que se halla en la raíz de la intervención de los diferentes sujetos en el trabajo: Le procedure per le nomine di vescovi: tra informazione e preferenza, Stato, Chiese e pluralismo confessionale 2 (2017) 1-35.

${ }^{17}$ En Alemania: Aachen, Köln, Essen, Freiburg, Fulda, Hildesheim, Limburg, Mainz, Münster, Osnabrück, Paderborn, Rottenburg, Trier; Salzburg en Austria; Basel, Chur y Sankt Gall en Suiza. Cfr. F. FABENE, «Provisión de las sedes episcopales», en Diccionario general de derecho canónico, VI, Instituto Martín de Azpilcueta, Pamplona 2012, 619; cfr. B. Primetshofer, La nomina dei vescovi nell'Austria, Germania e Svizzera, en D. J. ANDRÉs GuTIÉRREZ (ed.), Il processo di designazione dei vescovi. Storia, legislazione, prassi, PUL editrice, Città del Vaticano 1996, 511-539; P. V. A. BRAIDA, Elezione e nomina dei vescovi in Svizzera, en D. J. ANDrÉs GuTIÉRREZ (ed.), Il processo di designazione dei vescovi. Storia, legislazione, prassi, PUL editrice, Città del Vaticano 1996, 533-559. Para el caso de elección con confirmación en la Prelatura del Opus Dei, cfr. V. GómezIglesias C., L'Ordinazione episcopale del Prelato dell'Opus Dei, Ius Ecclesiae 3 (1991) 251-265; V. Gómez-Iglesias C., Circa l'elevazione all'Episcopato del secondo Prelato dell'Opus Dei, Ius Ecclesiae 7 (1995) 799-801.

${ }^{18}$ Cfr. M. Brogi, Elezione dei Vescovi Orientali Cattolici, en D. J. ANDrÉs GutiÉrREZ (ed.), Il processo di designazione dei vescovi: storia, legislazione, prassi, PUL editrice, Città del Vaticano 1996, 567-613; L. LoRUsso, La designazione dei vescovi nel Codex canonum ecclesiarum orientalium, Quaderni di Diritto Ecclesiale 12 (1999) 46-57. 
La unidad de la acción de provisión de un oficio capital se puede descomponer en tres dimensiones, estrechamente relacionadas entre ellas pero formal y cualitativamente diferentes. Estas dimensiones señalan las partes en que se articula el presente estudio. En primer lugar afrontamos la dimensión jurídico-sacramental implicada (según distintas modalidades) en la provisión de oficios capitales. En segundo lugar reflexionamos sobre la comunión jerárquica como situación personal que es objetivada en la provisión. En tercer lugar se estudian los aspectos de moderación del ministerio episcopal como sujeto colectivo (a distintos niveles), que son tomados en consideración en la provisión del oficio capital.

\section{LA DECISIÓN SOBRE LA ORDENACIÓN EPISCOPAL}

En un consistente número de casos, la provisión del oficio capital incluye la decisión acerca de la acción sacramental en sentido estricto, consistente en la elección de un presbítero para el ministerio episcopal y su efectiva ordenación como obispo. En este supuesto, la autoridad asume la responsabilidad de verificar las condiciones y requisitos para una válida y lícita ordenación episcopal.

En el plano subjetivo del candidato estas condiciones y requisitos no difieren particularmente de las que son requeridas para el acceso a los otros dos grados del orden sagrado. Que el derecho no prevea explícitamente una verificación de tales condiciones personales como en las otras órdenes (cfr. especialmente cc. 1024-1025 CIC y siguientes) no significa que los bienes que se protegen con tales exigencias personales sean menos importantes. Es obvio que son si cabe más importantes y que la ausencia en la persona de alguno de tales requisitos y condiciones (piénsese, por ejemplo, en anomalías psicológicas) podría conllevar consecuencias en principio más negativas que en el caso de diáconos o presbíteros.

Se puede considerar que el término temporal establecido normativamente como requisito de idoneidad («ordenado de presbítero desde hace al menos cinco años»; c. $378 \$ 1.4$ CIC) ofrece una base para una presunción en favor de la persistencia de las condiciones subjetivas que se poseían al tiempo de la recepción del orden del presbiterado ${ }^{19}$. Son las condiciones que motivaron el jui-

${ }^{19}$ El requisito objetivo de haber cumplido treinta y cinco años (c. $378 \$ 1.3$ CIC) no tiene un especial significado sustantivo; se trata de un requisito de derecho eclesiástico (que podría ser dispensado); Bier lo considera un «presupuesto formal» para el episcopado, que sirve exclusivamente para empezar a tomar en consideración (o, naturalmente, excluir durante un cierto tiempo) a ciertos sacerdotes (cfr. G. BIER, Die Rechtsstellung des Diözesanbischofs..., cit., 87). 
cio positivo de idoneidad por parte de la autoridad eclesiástica: «el Obispo (...) debe tener constancia (...) de que se ha probado de manera positiva la idoneidad del candidato, mediante la investigación realizada según derecho» (c. 1051 CIC). Precisamente por ese carácter presuntivo, no se exime a la autoridad de apurar, con los medios razonables a su disposición, tal persistencia, especialmente en el caso en que se hayan puesto en cuestión en algún momento de la vida del posible candidato al episcopado. Tal eventual cuestionamiento deberá emerger en algún momento del procedimiento de nombramiento de obispos y no se puede excluir que en el caso que sea probado, pueda mostrar la carencia de un requisito para el nombramiento episcopal ${ }^{20}$.

Junto a la responsabilidad en que puedan incurrir quienes intervienen en los procedimientos en caso de una falta de diligencia en el cumplimiento del propio deber, teniendo en cuenta las importantes implicaciones que conlleva la eventual llamada al episcopado, se podría configurar en los interesados como posibles candidatos un deber de manifestación de ciertas características personales que una persona tenga por objetivamente o subjetivamente impedientes para una llamada al episcopado ${ }^{21}$.

Naturalmente el término temporal mínimo de cinco años desde la ordenación presbiteral está también destinado a garantizar un mínimo de experiencia en el ejercicio del ministerio. De todos modos, el derecho no especifica la naturaleza de la experiencia en el ministerio durante esos años ${ }^{22}$. Parece

${ }^{20}$ En estos casos deberá tomarse alguna medida en relación a un presbítero que se halle en semejantes condiciones por carecer sobrevenidamente de la idoneidad para el orden sagrado. Aunque debería llamar la atención que esas circunstancias hayan emergido cuando ha sido tomada en consideración la hipótesis de su llamada al episcopado, es ésta una de las misiones encomendadas al examen de candidatos. No se piensa necesariamente en actitudes o hechos culpables; puede tratarse de un problema de salud que desaconseje abiertamente el acceso al episcopado; $a$ priori otros factores de tipo personal admiten valoraciones prudenciales. Este tipo de falta de idoneidad debería precluir en sí mismo el acceso al episcopado, sin llegar a tomarse en consideración el concreto oficio para el que se recaban informaciones sobre una cierta persona. Otros requisitos (no relativos a la idoneidad general para el orden sacro) pueden ser considerados desde una gradación, según sean las exigencias de la sede de que se trate; como afirma Bier, no todos los obispos están en la misma medida dotados para cualesquiera oficios episcopales (cfr. ibid.).

${ }^{21}$ Dejando de lado la vigencia a la que ya hemos aludido de los criterios generales sobre otros grados del orden (cfr. T. RINCÓN-PÉREZ, El orden de los clérigos o ministros sagrados. Formación, incardinación y estatuto jurídico personal, Eunsa, Pamplona 2009, 118-133) para el acceso al episcopado las adaptaciones obvias que deben hacerse no deberían dejar de recaer en los interesados, sin excluirse consecuencias serias en el caso de reticencia consciente y probada.

${ }^{22}$ En fase de elaboración del CIC se excluyó explícitamente que se concretase en el canon una especial experiencia pastoral, para evitar, se dijo, que se interpretara como obligatorio el haber sido párroco (cfr. Communicationes 12 [1980] 291). 
evidente que en la toma en consideración de la idoneidad de la persona este elemento temporal deberá proyectarse sobre las distintas facetas de la potencial misión episcopal.

Aunque formalmente no entren en las condiciones para la recepción del sacramento del orden en su grado supremo, el acto de provisión considerado desde la perspectiva del gobierno deberá incluir, en sede de valoración de la idoneidad personal del candidato, la que se corresponde con la sustancia sacramental del ministerio episcopal. En efecto, para el desarrollo de funciones episcopales son ineludibles unas ciertas condiciones objetivas, y son las que se corresponden con el ejercicio de los tres munera eclesiales en aquello que específicamente cualifica el ministerio episcopal, que es el ministerio de la comunidad, que en principio apunta a una participación en la capitalidad eclesial $^{23}$.

Para la valoración de estas condiciones objetivas no existe un paradigma abstracto que las defina como una base para ser obispo de «cualquier encargo episcopal», sino que se trata de un mínimo, que será circunscrito a posibles encargos que se puedan recibir a lo largo del tiempo teniendo también en cuenta la capacidad de aprendizaje y de adaptación ${ }^{24}$. Puede ayudar a situar estos parámetros la consideración según la cual muchos presbíteros, dotados para

${ }^{23}$ Este elemento se contiene en la misma ordenación episcopal: «El lugar del Obispo en el Pueblo de Dios proviene de su plenitud sacramental: la ordenación episcopal confiere el proprium del Obispo en cuanto episcopal y que le diferencia del ministerio de cooperación de los presbíteros, y de los diáconos. Su ministerio está orientado -a partir de su condición de miembro del Colegio episcopal- "ad habendam conditionem capitis in Ecclesia" (W. Bertrams)», J. R. VILLAR, Ministerio episcopal y laicado, en S. DEL CURA ElENA (ed.), El ministerio episcopal, Imprenta Santos, Burgos 2001, 201; la cita interna es de W. BERTRAMS, De differentia inter sacerdotium episcoporum et presbyterorum, Periodica 59 (1970) 195. Aunque escapa a las consideraciones de este trabajo, le referencia a la participación en la capitalidad episcopal reclama un juicio ponderado sobre aquellos oficios diferentes del oficio capital en una circunscripción eclesiástica. Una extensa praxis eclesial, cristalizada en el derecho positivo vincula una buena parte de los oficios ocupados por los obispos auxiliares o coadjutores a una tal participación y se justifica su existencia sobre esa base. Algo semejante se predica de una buena parte de los oficios auxiliares del Romano Pontífice, aunque en ocasiones sea legítimo preguntarse si realmente se trata de una participación en su específica capitalidad episcopal. Se podría decir que en los casos de obispos que hayan ocupado cargos carentes de una clara conexión con la capitalidad episcopal, su eventual traslado a un oficio de esa naturaleza reclama especialmente que se apuren precisamente las condiciones para la titularidad y ejercicio de los munera episcopales.

24 Ésta es una de las justificaciones que se aducen para dar razón de la figura de los obispos auxiliares (en menor medida de los coadjutores); de hecho, aunque depende generalmente de la estructura de oficios episcopales de un país, es corriente que el primer nombramiento como obispo auxiliar en un oficio que es consistente con la condición episcopal personal, se realice también como preparación eventual a un ulterior nombramiento como titular de un oficio capital. 
los ministerios específicos de este grado del orden, no lo están en relación a las que normalmente corresponden a un obispo.

Un criterio de idoneidad para la ordenación episcopal es el relativo a una cualificación (vere peritus) en «sagrada Escritura, teología o derecho canónico» (c. $378 \$ 1.5$ ). En principio esta cualificación se da por acreditada cuando se posee un doctorado o una licenciatura en alguna de esas áreas, con un título atribuido a la persona en «un instituto de estudios superiores aprobado por la Sede Apostólica». La verificación de una cualificación sustancial (vere peritus) según una praxis consolidada por parte de la Sede apostólica, debería resolver los casos menos claros, especialmente cuando las necesidades pastorales son apremiantes. Parece claro que en definitiva se exige una cierta habilidad fundada en el estudio, en materias relativas a la vida eclesial, más allá de la exigida para la recepción del sacramento del orden en el grado del presbiterado ${ }^{25}$.

El c. $378 \$ 1.2$ CIC establece como requisito para los candidatos al episcopado la buena fama (bona exsistimatione gaudens). Una referencia a la historia de la redacción del canon ayuda a la comprensión de una característica que por sí misma no debería ser exclusiva de una persona que puede ser llamada a ser obispo. La formulación del canon responde a la discusión, en sede de elaboración del CIC, acerca del requisito contenido en el CIC-1917 que reclamaba en los candidatos al episcopado la condición de hijos legítimos ${ }^{26}$ (c. 331 $\$ 1.1$ CIC-1917). Esa discusión versaba en definitiva sobre el alcance de este requisito; cuando se polarizaron las posiciones acerca de la supresión o no de tal presupuesto, uno de los consultores propuso la alusión a la «buena fama» de la persona de que se trate y que se vea caso por caso si una cierta carencia en este ámbito -no sólo la relativa a la filiación- puede considerarse un demérito o aun una inidoneidad en vista a la llamada al episcopado ${ }^{27}$. La nueva orientación, junto a una cierta evolución social acerca de la filiación, evoca un ligero cambio de acento en la consideración de la condición episcopal, desde

${ }^{25}$ Ésta es básicamente la orientación de Bier (cfr. G. BIER, Die Rechtsstellung des Diözesanbischofs..., cit., 89). Una praxis algo extendida que no sigue el dictado del derecho positivo consiste en no exigir la Licencia o el Doctorado eclesiástico a quienes poseen un título universitario civil.

${ }^{26} \ll$ Ut quis idoneus habeatur, debet esse: Natus ex legitimo matrimonio, non autem legitimatus etiam per subsequens matrimonium». La norma de la inhabilidad aun mediando legitimación (c. 1116 CIC-1917) se aplicaba también a cardenales (c. $232 \$ 2.1$ CIC-1917) y prelados nullius (c. $320 \$ 2$ CIC-1917) pero no a los candidatos al seminario (c. 1363 CIC-1917), según una interpretación auténtica de la Comisión Pontificia para la interpretación de los cánones de código de 13 de julio de 1930 (AAS 22 [1930] 365).

27 Cfr. Communicationes 24 (1992) 33-36. 
la dignidad institucional del episcopado hacia la condición de servicio de la persona llamada. Desde el punto de vista operativo se pasa de un requisito legal objetivo en relación a la persona a una valoración sobre cómo es percibida por la comunidad la personalidad del posible candidato.

En esta línea, hay que señalar que en términos generales la perspectiva del episcopado sitúa al candidato en el ámbito de las personas con relevancia pública e institucional, y por lo tanto es objeto de la atención de las autoridades civiles y de los medios que configuran la opinión pública. Es ésta una cuestión de la que no se puede prescindir y que trae consigo no pocas implicaciones que van más allá de la «buena fama» en la comunidad eclesial y en relación a los bienes eclesiales fundamentales. Este requisito se extiende notablemente y debe ser tomado en consideración como parte de la responsabilidad para la provisión de oficios capitales, en la línea de nombrar personas con una objetiva consideración positiva y sobre las que no pesen cuestionamientos de fiabilidad personal ${ }^{28}$.

${ }^{28}$ No puede dejar de pensarse en eventuales procesos administrativos o judiciales pendientes en los que esté implicado un candidato; sea porque pueden reflejar una falta de pericia o de rectitud personal o porque se han puesto en cuestión; mientras no se haya apurado la inocencia del sujeto, raramente prosperará un candidato con antecedentes de esta naturaleza. Se añade aquí el problema de la falta de fiabilidad de algunos sistemas judiciales, del recurso abusivo a los tribunales o de las acusaciones formuladas de mala fe. Son otros tantos riesgos para que un límite de esta naturaleza -en sí mismo más que legítimo- deba ser valorado con las debidas garantías. La prevalencia de la forma pública de cuestionamiento de las cualidades en los eventuales candidatos adquiere en la actualidad perfiles marcados de forma notoria cuando se hace presente ante la opinión pública. En efecto, en nuestros días el cuestionamiento de un posible candidato puede salir a relucir en el ambiente de la opinión pública (eclesial o no), en ocasiones como posición de parte. A nadie se oculta que a veces tal cuestionamiento se verifica de forma poco honesta ya sea porque se subraya una cierta vacilación (o una posición rigorista) en un aspecto doctrinal o de disciplina sacramental, o porque se cuestiona la capacidad o incluso la voluntad del interesado de colaborar con el episcopado local o nacional, o por la ausencia (o exceso, descuidándose otros aspectos pastorales) de actividad caritativa o la poca atención a la liturgia, etc. Es claro que en ocasiones tales insinuaciones se dirigen a influir en los procedimientos de valoración de requisitos que se hallan en curso. En el ámbito de gobierno en el que se mueven estas consideraciones, más allá de que conste fehacientemente la situación de comunión de una persona, la labor de discernimiento se juega en estos ámbitos ciertamente complejos y en ocasiones difíciles de definir y valorar. Puesto que este tipo de decisiones no son meramente discrecionales sino que, dentro de ciertos límites, encierran una responsabilidad relativa a la facilitación de buenos pastores para el pueblo de Dios, no se debe descartar que en ocasiones un nombramiento deba producirse contra una inicial o incluso persistente manifestación de resistencia de una parte de la comunidad, de la autoridad pública o de grupos de interés determinados. Uno de los documentos que suelen usarse para el procedimiento de nombramiento de obispos (en adelante «Cuestionario») contiene un epígrafe sobre este tema, formulado así: «Imagen (o estimación) pública: ¿es respetado por sus hermanos clérigos? ¿Y por el pueblo (el público en general) y las autoridades?». 
La referencia del c. 378 CIC a una serie de virtudes del candidato al episcopado si bien se puede considerar ejemplificativa ${ }^{29}$, no carece de relevancia a los efectos de la tarea de información y verificación de quienes intervienen en los procedimientos. En buena parte un criterio de responsabilidad es el que cierra la enumeración de esas notas personales; en el candidato se quiere ver si concurren «las demás cualidades que le hacen apto para ejercer el oficio de que se trata» (c. $378 \$ 1.1$, in fine $\mathrm{CIC})$.

El discernimiento para la ordenación episcopal está ligado a las legítimas expectativas de los fieles. A estas condiciones más específicas nos referiremos más adelante al tratar de la perspectiva del concreto oficio en vista al cual una determinada persona es ordenada como obispo, pero no se puede pasar por alto que la referencia sacramental al «ministerio de la comunidad» (LG 20c) atrae criterios de valoración y consecuentemente de verificación en sede de idoneidad, estrechamente vinculados a la razonable expectativa de los fieles acerca de sus pastores. En efecto, las situaciones jurídicas formalizadas en los cánones 212-213 CIC están en la base de la disciplina sobre la provisión de oficios y con mayor razón sobre la provisión de los episcopales: se debe obediencia a los pastores en lo que declaran o disponen precisamente en cuanto representan a Cristo (c. $212 \$ 1 \mathrm{CIC}$ ); éstos a su vez, como deber prioritario, están obligados a dar los bienes espirituales de la Iglesia a los fieles (c. 213 CIC). Las instancias responsables de la provisión de oficios eclesiales están ligadas a garantizar razonablemente en los obispos la capacidad para la representación de Jesucristo y para otorgar esos bienes espirituales; ambas dimensiones en su expresión plena

\footnotetext{
Usamos la versión del «Cuestionario» para el procedimiento de nombramiento de obispos publicado en T. J. ReESE, The Selection of Bishops, America Magazine, Aug. 18 (1984), que coincide en sus líneas fundamentales con otras versiones en diferentes idiomas publicadas posteriormente en internet. Para algunas reflexiones sobre el tema, cfr. R. B. SHAw, Nothing to bide: secrecy, communication and communion in the Catholic Church, Ignatius Press, San Francisco (CA) 2008; N. González Gaitano, Public opinion and the Catholic Church. A theoretical perspective, en Public opinion and the Catbolic Church, Edusc, Roma 2010, 9-47.

${ }^{29}$ Se recogen las mismas contenidas en el c. $331 \$ 1.4$ CIC-1917 añadiéndose «firma fides», «sapientia» y junto a la «prudentia» una referencia general a las virtudes humanas; se añade asimismo un grado especial en relación al conjunto de esas características: «excellens». En lugar de la referencia al gobierno de la diócesis del CIC-1917, el punto de referencia que se establece para valorarlas es «el oficio de que se trata». Además de las que se desprenden de los documentos magisteriales o curiales sobre el episcopado, otras referencias a virtudes y caracteres personales del perfil de los candidatos se hallan en el art. VI.2 de las Normae de promovendis ad Episcopatum in Ecclesia latina de 1972 (asimismo en el «Cuestionario» donde se ejemplifica la piedad con la celebración diaria de la Eucaristía y de la Liturgia de las Horas, así como de la devoción mariana).
} 
(episcopado), capital (generalmente con el ministerio de presidencia de la comunidad) y con una razonable proyección temporal ${ }^{30}$.

Como hemos indicado, la provisión de oficio episcopal posee también la dimensión integradora del sujeto en el «ministerio episcopal». Sin necesidad de dilucidar aquí los factores causantes de esa integración personal, cada provisión del oficio episcopal supone una decisión de gobierno sobre el colegio episcopal: una nueva incorporación si se refiere a un nuevo obispo o una modificación si se trata del traslado de un oficio a otro u otras determinaciones. En efecto, si se comprende el ministerio episcopal y por ende el colegio episcopal como una instancia corporativa viva, integrada en cada momento histórico por los obispos del mundo, sería artificioso pensar que están en dicho colegio como obispos al margen de su efectiva función. Precisamente hacen presente en el interior del sujeto corporativo con su vida configurada sacramentalmente y con el ministerio inherente a su oficio (con mayor razón si es un oficio capital) la universalidad y la catolicidad de la Iglesia ${ }^{31}$.

No nos corresponde tampoco aquí ilustrar las funciones de un miembro del colegio episcopal, como tal miembro. Señalamos únicamente que a los efectos de valorar la idoneidad para ser obispo (para la provisión del oficio en su caso) este horizonte de funciones no podrá ser pasado por alto. Las cuestiones que deberán suscitarse son las que definen los perfiles de una participación efectiva en el colegio episcopal: que esa persona se halla en condiciones de realizar una aportación positiva a uno de los sujetos de la potestad suprema de la Iglesia, que es un digno sujeto personal de la sucesión apostólica, que puede ofrecer una aportación fiablemente constructiva al magisterio ordinario y universal de la Iglesia católica y a un eventual Concilio ecuménico, que se halla en condiciones sostener la específica fraternidad episcopal que conllevará su nueva condición, etc.

El hecho de que estas cuestiones se tomen en consideración sólo reflejamente en el procedimiento que conduce a la provisión de un oficio episcopal (ya que las consideraciones que predominan afectan sobre todo a dotar de un

${ }^{30}$ La coherencia sacramental a la que se hace referencia en el texto cuestionaría la eventual llamada al episcopado por motivos diferentes de los vinculados a un servicio (por ejemplo, por motivos honoríficos o la que pudiera eventualmente derivar de un nombramiento a un oficio creado $a d$ boc incluso para ofrecer protección a una persona, etc.).

31 Desarrollamos más detenidamente esta dimensión de la provisión desde la perspectiva del ministerio episcopal, en «La provvista dell'ufficio capitale come azione di governo relativa all'organizzazione istituzionale della Chiesa» (en fase de publicación). 
justo pastor para la sede determinada) nada dice en contra de que se encierran precisamente en tal decisión de gobierno. En efecto, no hay otro cauce institucional para la configuración histórica del sujeto «ministerio episcopal» que el nombramiento para oficios que conllevan o presuponen la ordenación al episcopado. Por otro lado, la reflexión eclesial acerca de la sacramentalidad del episcopado ha dilucidado la existencia de una específica dimensión sacramental -y no simplemente de atribución y posesión de funciones- intrínseca a la incorporación de una persona al orden de los obispos por efecto de la ordenación ${ }^{32}$. Existe pues una específica novedad sacramental en la persona, que está en la base de la atribución de las funciones episcopales específicas. En efecto, agregando nuevos miembros al ministerio episcopal se mantiene según el mandato del Señor la estructura sacramental a través de la cual gobierna a su Iglesia ${ }^{33}$, y esto se realiza a través de los actos de provisión que conllevan la incorporación de nuevos miembros al ministerio episcopal.

Un aspecto de esta estructura sacramental se explicita en la afirmación según la cual no existe un derecho a ser obispo ${ }^{34}$. Junto a la cuestión de las motivaciones subjetivas (el carácter «pasivo» de la vocación y su sentido de servicio) y a la voluntad providente de Dios en el gobierno de la Iglesia, tal afirmación subraya la existencia de unos cauces institucionales para la elección de personas al ministerio episcopal, que encierran las garantías necesarias para el cumplimiento de su misión a lo largo de los tiempos. Uno de estos cauces institucionales es la imposición de la manos -como núcleo de la ordenación episcopal- que debe ser realizada constantemente con la intención de prolongar la misión confiada a los apóstoles por el Señor, al margen de cualquier interés ul-

32 Cfr. J. LÉCUYER, Le sacrement de l'ordination: recherche historique et théologique, G. Beauchesne, Paris 1983; J. LÉCUYER, L'episcopato come sacramento, en G. BARAÚNA (ed.), La Chiesa del Vaticano II. Studi e commenti intorno alla costituzione dommatica «Lumen gentium», Vallecchi, Firenze 1965, 713-732.

${ }^{33}$ En referencia al munus regendi jerárquico, Benedicto XVI se refería a una «estructura de autoridad sacramental en la Iglesia, ordenada según los tres niveles del sacramento del Orden: episcopado, presbiterado y diaconado» (BENEDICTO XVI, Audiencia, 26-V-2010, en Insegnamenti di Benedetto XVI, vol. 6.1, Libreria Editrice Vaticana, Città del Vaticano 2011, 779).

${ }^{34} \mathrm{La}$ formulación del Catecismo de la Iglesia Católica se refiere a todos los grados del sacramento del orden. Aunque tiene especialmente presente el del diaconado y presbiterado, tiene su aplicación también al grado del episcopado: «Nadie tiene derecho a recibir el sacramento del Orden. En efecto, nadie se arroga para sí mismo este oficio. Al sacramento se es llamado por Dios (cfr. Hb 5,4). Quien cree reconocer las señales de la llamada de Dios al ministerio ordenado, debe someter humildemente su deseo a la autoridad de la Iglesia a la que corresponde la responsabilidad y el derecho de llamar a recibir este sacramento. Como toda gracia, el sacramento sólo puede ser recibido como un don inmerecido» (Catecismo de la Iglesia Católica, n. 1578). 
terior como sería una pretensión personal del interesado o de otros sujetos que se arrogaran derechos en su favor ${ }^{35}$. La valencia sacramental del signo y de sus efectos estimula a una purificación constante de las motivaciones para la provisión de oficios episcopales, tanto en las autoridades implicadas como en los posibles candidatos.

\section{LA ACREDITACIÓN DE LA «COMUNIÓN JERÁRQUICA»}

Tanto para obtener en plenitud operativa la condición episcopal como para ejercitar legítimamente un oficio episcopal es necesaria la situación de comunión jerárquica. En consecuencia ésta debe ser acreditada en sede de provisión de oficios episcopales, que con frecuencia incluyen el mandato para la ordenación. Como es sabido, la situación de comunión jerárquica se halla estrechamente ligada a la dimensión sacramental propia de la ordenación y de la incorporación al ordo episcoporum. Prestamos atención a esta dimensión de la provisión que expresa propiamente que consta la comunión jerárquica del candidato en los bienes eclesiales que la constituyen, con la Cabeza del colegio y con el colegio episcopal como tal.

Más allá de las importantes temáticas implicadas en la compleja cuestión de la naturaleza y contenido de la comunión jerárquica, sobre todo en relación al sacramento del orden, a nuestros efectos tenemos que dilucidarla como la constancia de una cierta situación de la persona, objetiva y suficientemente estable como para ofrecer una base en virtud de la cual puede desarrollar la misión episcopal.

Es relevante recordar que la comunión jerárquica es constitutiva de una dimensión interpersonal y externa requerida para la plena operatividad de la condición episcopal, considerada en sí misma y en conexión con el colegio episcopal ${ }^{36}$. En efecto, siguiendo la Nota explicativa previa de Lumen Gentium,

\footnotetext{
35 A lo largo de la historia la Iglesia tiene que actualizar los medios para discernir quienes son llamados a tal ministerio, hallando personas dotadas y capaces para ser buenos pastores, y evitando la prevalencia de intereses -personales o corporativos- que mundanicen el ministerio. A este propósito es ejemplificativa la articulación de medios jurídicos de los que se ha valido la Iglesia para desenmascarar formas de renuncia que ocultaban provisiones de oficios en favor de terceros, con la pretensión de imponerlas a las autoridades competentes para los nombramientos (cfr. P. G. CARON, La rinuncia all'ufficio ecclesiastico nella storia del diritto canonico dalla età apostolica alla riforma cattolica, Vita e pensiero, Milano 1946).

${ }^{36}$ Nos hemos ocupado de esta cuestión en el trabajo «La provvista dell'ufficio capitale come azione di governo relativa all'organizzazione istituzionale della Chiesa» (en fase de publicación).
} 
el sentido de la comunión «no es el de un afecto indefinido, sino el de una realidad orgánica, que exige una forma jurídica y que, a la vez, está animada por la caridad». Su persistencia como condición de posibilidad de la existencia de un miembro del colegio episcopal y de la operatividad plena de los munera apunta a su acreditación en sede tanto de la llamada al episcopado como de la provisión del oficio episcopal.

Convenimos sustancialmente con Arrieta en su análisis de la norma general relativa a la comunión requerida para todos los oficios eclesiásticos (c. $149 \$ 1 \mathrm{CIC}$ ): «mientras que el aspecto negativo del requisito [de la comunión] se cumple estrictamente con la sola ausencia de censura eclesiástica que lleve consigo la condición subjetiva de excomulgado, la dimensión positiva del precepto, ciertamente incluida en el requisito del canon, postula además una activa situación personal de comunión eclesiástica»; el autor se refiere a los tres vínculos de la comunión, para añadir «es obvio, por otro lado, que mientras el aspecto negativo del requisito deba aplicarse con igual medida a la provisión de cualquier oficio eclesiástico, la dimensión positiva deba exigirse en una relación de proporcionalidad respecto de la naturaleza y de las funciones eclesiales propias de cada oficio concreto» ${ }^{37}$.

Vemos ahora cómo se explicita este análisis en el caso de los oficios capitales.

En la acción de provisión del oficio episcopal se procede habitualmente sobre la base de una presunción de comunión efectiva en los presbíteros cuyas condiciones se toman en consideración. Es decir, ya sea en el proceso de selección de futuros obispos como, con mayor razón, en la decisión de llamar a una persona al episcopado para un concreto oficio, los sujetos que intervienen parten de la base de que tal comunión es real, efectiva y vigente. Sólo la presencia de hechos obstativos de tal supuesto serán efectivamente objeto de verificación para ser confirmados o desmentidos, con la consiguiente inclusión o desestimación del candidato. En este sentido podemos decir que en relación a la comunión necesaria como presupuesto para ser llamado al episcopado y para estar en condiciones de ejercitar las correspondientes funciones, predo-

37 J. I. Arrieta, sub 149, en Á. MarzoA - J. Miras - R. RodrígueZ-OCaÑa (eds.), Comentario exegético al Código de derecho canónico, Eunsa, Pamplona 1996. Cfr. también B. EJEH, The principle of suitability in the provision of ecclesiastical offices in the 1983 Code of Canon Law, Ius Ecclesiae 20 (2008) 579-580; A. MigliavaCCA, «Idoneidad para oficios y ministerios», en Diccionario general de derecho canónico, IV, Instituto Martín de Azpilcueta, Pamplona 2012, 361-365; A. VIANA, La comprobación de la idoneidad para el oficio eclesiástico y el orden sagrado, Ius Ecclesiae 28 (2016) 345-366. 
mina el aspecto negativo de exclusión de circunstancias que puedan cuestionar la comunión.

Este aspecto negativo adquiere relevancia más por la forma en que se manifiesta -en principio pública o notoria-, que por el contenido del vínculo de comunión en que se perciban carencias o que eventualmente se cuestione. Como señala Arrieta, la ausencia de una censura de excomunión es el caso paradigmático de este aspecto, ya que por su aplicación de modo público y como consecuencia de una grave lesión de bienes eclesiales la persona se sitúa fuera del cuerpo visible de la Iglesia ${ }^{38}$. Pero hay que notar que en el ámbito del que nos ocupamos, prácticamente cualquier sanción, sobre todo penal, irrogada a un sujeto (a un sacerdote en el caso que nos ocupa), que significa la privación de algún bien eclesial, lo excluirá de modo casi automático de la posible designación. A semejante conclusión conducirá asimismo la sujeción a un procedimiento sancionador de cualquier naturaleza, mientras no se resuelva de forma claramente absolutoria en favor del candidato. El requisito de la comunión, que en sí misma ofrece perfiles eclesiales definidos, se materializa en una necesaria exclusión de este tipo de situaciones.

En este sentido, aunque los procedimientos de selección de candidatos al episcopado prevén que se tome en consideración este elemento, en ausencia de signos claros de discordancia con tales vínculos, prevalecerá la presunción de comunión efectiva a la que nos hemos referido. Con todo, un juicio de ausencia de comunión no puede basarse en simples suposiciones o meras deducciones a partir de acciones o palabras de una persona, sino que debería constar y ser probada de modo fehaciente ${ }^{39}$.

${ }^{38}$ Formalmente se trata de los supuestos del c. $1331 \$ 1.2$ (exclusión del sacramento) y 2.4 (exclusión de la obtención del oficio) CIC. Cfr. J. BERNAL, «Excomunión», en Diccionario general de derecho canónico, III, Instituto Martín de Azpilcueta, Pamplona 2012, 835-840. Presuponemos una excomunión ferendae sententiae o latae sententiae declarada.

39 El tema de la acreditación de la comunión ofrece perfiles más graves en caso de que sea sobrevenida: mientras en el contexto de la provisión la consecuencia es el descarte del posible candidato, que al fin y al cabo no posee ni un derecho ni una posición consolidada, en el caso de un titular efectivo de un oficio capital, en el horizonte de una remoción, la situación es totalmente distinta. La misión de quienes se encargan de verificar la comunión en fase de provisión es en todo caso importante; no se puede descartar que en alguna ocasión las instancias encargadas de la promoción al episcopado hayan obrado con criterios de tolerancia, más o menos justificada o implícita, quizás en los casos de escasez de personas claramente idóneas, que se han revelado problemáticas. No puede dejar de destacarse el hecho de que el «Cuestionario» prácticamente sólo concrete un aspecto tan amplio como la comunión en el régimen, en la cuestión del celibato sacerdotal. Aunque depende de otros factores (por ejemplo, que el tema se viva con especial tensión en el país o la extensión de las vacilaciones que puedan existir en un determinado con- 
La no existencia de elementos obstativos supone un primer filtro para la acreditación de la comunión jerárquica; el aspecto positivo de la verificación de los vínculos de comunión además de ser más complejo, se efectúa de modo generalmente amplio y tal vez en ocasiones vago. Es más complejo porque no resulta fácil afirmar sin más que una persona, un sacerdote que desarrolla normalmente su actividad pastoral se halla fuera de los límites de la comunión, y menos aún que en la eventualidad de ser llamado al episcopado promoverá de forma activa en favor de los fieles los vínculos en que consiste.

Sin duda debería servir de parámetro positivo para esta acreditación el criterio de la proporcionalidad entre los grados de comunión y las funciones ínsitas en el oficio concreto al que se es llamado. No se puede perder de vista que, tratándose de un oficio episcopal, el sujeto no sólo está llamado, como todo fiel, a estar en comunión como situación personal visible (c. 205 CIC). Tampoco se puede conmensurar el grado de comunión con la común dimensión pública del oficio eclesiástico, del que legítimamente se espera una representatividad eclesial por el hecho de ejercitar funciones públicas (c. 149 CIC) ${ }^{40}$. En el caso que nos ocupa de los oficios de capitalidad episcopal nos hallamos ante una exigencia de comunión particularmente cualificada.

\footnotetext{
texto), habrá que distinguir las situaciones en vista de un posible nombramiento. No tendrá la misma relevancia que un sacerdote haya manifestado en privado dudas sobre la conveniencia de la disciplina; la adhesión más o menos formal a una plataforma reivindicativa de la abrogación de esa disciplina; la constancia de que una persona en una ocasión lejana en el tiempo ha faltado a tal compromiso; la constancia de una persona que vive en un concubinato de hecho más o menos conocido. Somos conscientes de que en los ejemplos planteados se mezclan cuestiones personales relacionadas con la moralidad y aproximaciones doctrinales que más bien habría que considerar en el contexto de la fe firme que se pide a un candidato, con actitudes que pueden hacer prever una mayor o menor exigencia en promover la efectiva vigencia del celibato eclesiástico en la diócesis. Es una muestra de que el juicio de idoneidad no puede ser objeto de compartimentación. Se puede cuestionar la gradación del problema en un ámbito real; sin embargo, no cualquier grado admite la tolerancia.

${ }^{40}$ A efectos explicativos se distinguen legítimamente unos y otros vínculos (M. VISIOLI, La comunione ecclesiale: rilievi canonistici, en GRUPPO ITALIANO DOCENTI DI DIRITTO CANONICO [ed.], La comunione nella vita della Chiesa: le prospettive emergenti dal Vaticano II, Glossa, Milano 2014, 35 36; G. GHIRLANDA, «Comunione ecclesiale/ecclesiastica/gerarchica», en C. CORRAL - V. DE PaOlis - G. GhiRlanda [eds.], Nuovo dizionario di diritto canonico, Edizioni Paoline, 1993, 209214). Sin embargo, no conviene perder de vista que los vínculos de la comunión no son reductibles a relaciones meramente subjetivas. Análogamente a como se expresa la Nota explicativa previa de LG, no se trata de «un afecto indefinido», una cierta paz social o armonía colectiva entre los fieles, de los fieles con los pastores y de los pastores entre ellos; se trata más bien de la posesión común, según la respectiva posición eclesiológica (LG 10: orgánica es también la ordenación recíproca entre el sacerdocio común y el sacerdocio ministerial) de los bienes de la comunión. Precisamente el ministerio eclesiástico -y particularmente el ministerio episcopal-
} 
En quien es llamado al episcopado tal comunión personal adquiere una consistencia específica ya que por ella es llamado a constituir el sujeto personal y corporativo alrededor del cual se establecen esos vínculos, y, siempre junto con la Cabeza (LG 22) el garante último de tal comunión. En este sentido, en un primer nivel, la comunión se corresponde no sólo con la posesión pacífica de los bienes en que consisten los vínculos de comunión sino la capacidad -suficientemente verificada- de testimoniarlos en la perspectiva de la dimensión universal del ministerio episcopal. En un segundo nivel la capacidad de testimoniar y sostener la comunión se proyectará sobre las relaciones con la comunidad de fieles en relación con la cual el candidato será referente de la comunión. En todo caso, la comunión jerárquica muestra su carácter relacional, sobre todo por lo que supone de responsabilidad frente a la comunidad, y en referencia a la posesión colectiva (del sujeto «ministerio episcopal» tomado en su conjunto) de los bienes de la comunión, base imprescindible para su conservación y transmisión.

La medida relacional de la comunión se debe valorar -en fase de provisión del oficio episcopal- sobre la base de las vinculaciones existentes con los demás obispos y con el Romano Pontífice, así como la proyección de esa relación en el tiempo ${ }^{41}$. Naturalmente no se trata de entrar en cuestión acerca de relaciones personales más o menos ricas sino propiamente en la capacidad de ejercitar las funciones de garantía de los bienes eclesiales constitutivos de la comunión en la regla de la fe, en los sacramentos y en el gobierno, precisamente en el nivel episcopal.

tiene encomendadas funciones de garantía de autenticidad y veracidad que son constitutivas de los bienes mismos y de los vínculos de comunión que generan. Este aspecto no hace de la jerarquía el sujeto eclesial fundamental, sino que hace posible ministerialmente la posesión común y verificable entre los fieles, que por ende es jurídica en lo que supone de deberes recíprocos de conservación y transmisión.

41 Una prueba de lo que se indicaba en la nota precedente es que para aquilatar la comunión para ser obispo no se puede dejar de lado la valoración de una explícita capacidad de unir a los fieles alrededor precisamente de los bienes constitutivos de los vínculos de la comunión. Es claro que un simple liderazgo humano (carismático, social, intelectual) debe estar acompañado y penetrado de una decisiva y preponderante conducción a los bienes salvíficos -en último término hacia la Eucaristía- y a la unión que se basa en ellos. Cfr. SACra Congregatio pro Episcopis, Dir. Apostolorum successores per il ministero pastorale dei vescovi (22-II-2004), Libreria Editrice Vaticana, Città del Vaticano 2004, n. 8. Algún aspecto de este tema lo afrontamos más adelante en cuanto no se trata de una cualidad que se pueda valorar sólo en abstracto sino que se debe tener en cuenta la relación con la porción del Pueblo de Dios de la circunscripción eclesiástica para la que se es nombrado y de las circunscripciones más próximas (con sus pastores) donde pueda proyectarse la actividad de gobierno pastoral. 
Una expresión formal de esta comunión cualificada se halla positivizada en el deber de emisión de la professio fidei y del juramento de fidelidad ${ }^{42}$ (cc. 380, 833.3 CIC) en vista al acceso al episcopado y al oficio episcopal.

No está muy claro que en la redacción del c. 378 CIC, el legislador tuviera reflejamente presente los vínculos y los bienes de la comunión. No hace falta en efecto una explícita positivación de los mismos en ese contexto, pero no puede dejar de destacarse que se incluye el requisito de la firma fides (c. 378 $\$ 1.1$ ) sin referencia a la disciplina o al régimen, y al munus sanctificandi ${ }^{43}$.

En relación a la rectitud doctrinal, que no figuraba explícitamente entre los requisitos del precedente c. $331 \mathrm{CIC}-1917$ y que fue introducido sin especial discusión en sede de elaboración del nuevo código ${ }^{44}$, es claro que trasciende la simple constatación de que el candidato es personalmente «ortodoxo»y menos aún que simplemente no se conozcan por su parte opciones doctrinales dudosas. Se trata más bien de que se acredite la personal y objetiva participación en el bien eclesial constitutivo del vínculo de la profesión de fe (c. 205 CIC) ${ }^{45}$. Como decíamos, no se debería dar especial importancia a la ausencia

42 Para la professio fidei, los obispos usan la fórmula establecida en CONGREGAZIONE PER LA DoTTRINA DELLA FEDE, Professio fidei et Iusiurandum fidelitatis, AAS 81 (1989) 104-106. En cambio, se usa una fórmula específica de iusiurandum fidelitatis que subraya especiales componentes de la comunión jerárquica específicamente episcopal («Formula iusiurandi fidelitatis ab Espiscopis praestandi»; cfr. R. RYвaK, La visita «ad limina apostolorum» nei documenti della Santa Sede e nel Codice di diritto canonico del 1983, Pontificia Università Lateranense, Romae 1994, 162-163, allegato I).

43 Bier señala que no todos los requisitos del c. $378 \$ 1$ CIC tienen igual valor sino que tienen prioridad los que se refieren a la fe recta y a la disciplina, al fin y al cabo porque se corresponden decisivamente con la comunión jerárquica; cfr. G. BIER, Die Rechtsstellung des Diözesanbischofs..., cit., 93. El «Cuestionario» es bastante explícito tanto en lo que se refiere a la fe como a la disciplina. Por lo que se refiere a la fe recta, se expresa así: «Ortodoxia: Adhesión convencida y lealtad a la doctrina y al magisterio de la Iglesia. En particular, la actitud del candidato en relación a los documentos de la Santa Sede sobre el sacerdocio ministerial, la ordenación sacerdotal de mujeres, el sacramento del matrimonio, la ética sexual y la justicia social. Fidelidad a la genuina tradición eclesial y compromiso en favor de la renovación auténtica promovida por el Concilio Vaticano II y por los subsiguientes enseñanzas pontificias». Al parecer para algunos países o para casos concretos se especifican ulteriormente algunos documentos del magisterio universal o incluso local; en relación a la disciplina, el «Cuestionario» se expresa así: «Disciplina: Lealtad y docilidad al Santo Padre, a la Sede apostólica y a la jerarquía; estima y aceptación del celibato sacerdotal tal y como lo expone el magisterio eclesiástico; respeto y observancia por las normas generales y particulares; en especial en relación a la liturgia y al traje clerical» (cfr. T. J. REESE, The Selection of Bishops, cit.).

${ }^{44}$ Cfr. Communicationes 24 (1992) 316.

45 Bier explicita que se trata de manifestar la adhesión a las realidades y en los modos expresados en los cc. 750 y 752 CIC (cfr. JuAn PABLO II, Carta Apostólica en forma de Motu proprio de S.S. Juan Pablo II «Ad tuendam fidem», AAS 90 [1998] 457-461), según las explicaciones de la «Nota doctrinal ilustrativa de la fórmula conclusiva de la Profesión de Fe», publicada por 
en el Código de una explícita referencia a la comunión jerárquica en relación a los vínculos de los sacramentos y del régimen eclesiástico (c. 205 CIC), teniendo en cuenta de que se imponen por sí mismos en quien desde una posición de capitalidad tendrá como primario empeño mantener y enriquecer estos vínculos en relación a todos los fieles (cc. 386, 387, 392, $835 \$ 1 \mathrm{CIC}{ }^{46}$.

La situación de comunión jerárquica y su acreditación en el contexto de la provisión de un oficio episcopal no es la única circunstancia que hay que tomar en consideración. Es también relevante una reflexión sobre esa condición de la persona, en clave de relación con otros sujetos. En efecto, ex post, la incorporación de un sujeto al colegio episcopal y el nombramiento como titular del oficio capital de una determinada circunscripción (por vez primera o en ocasiones sucesivas), genera de forma inmediata en relación a él una «consolidación» de la situación de comunión. En efecto, la verificación de la comunión jerárquica no supone una simple certificación de una posición más o menos abstracta en relación a ciertos contenidos, sino una acción de la autoridad eclesiástica que la refrenda públicamente. Ciertamente la comunión se valora de un modo objetivo en relación a los bienes eclesiales correspondientes pero, especialmente en lo que se refiere a la comunión en el régimen, responde también a una situación como es la de «ser considerado» en comunión por los demás copartícipes en esos bienes: con los demás obispos como sujeto de la comunión, con la Cabeza del colegio y en su nivel específico en relación a los fieles, más inmediatamente en relación a los fieles de la circunscripción de la que es centro de comunión ${ }^{47}$. Esta apreciación, por lo demás bastante simple,

la Congregación para la Doctrina de la Fe, L’Osservatore Romano del 30 de junio-1 de julio de 1998 (G. BIER, Die Rechtsstellung des Diözesanbischofs..., cit., 90-91). Sobre los obispos como «doctores y maestros auténticos de los fieles encomendados a su cuidado» (c. 753 CIC), cfr. G. GÄNSWEIN, «I vescovi ... sono autentici dottori e maestri della fede». Annotazioni sulla genesi e l'interpretazione del can. 753 CIC, Ius Ecclesiae 14 (2002) 135-155.

${ }^{46} \mathrm{La}$ «Formula iusiurandi fidelitatis ab Episcopis praestandi», hace referencia específica al ejercicio de estos dos munera en comunión jerárquica: «Apostolica munera Episcopis commisa, nempe populum Dei docendi, sanctificandi et regendi, in hierarchica communione cum collegii episcopalis capite atque membris, summa diligentia exsequenda curabo» (...) «Disciplinam cunctae Ecclesiae communem fovebo et observantiam omnium legum ecclesiasticarum, earum imprimis quae in Codice Iuris Canonici continentur, sollerter insistam, semper advigilans, ne mali usus irrepant praecipue circa ministerium verbi et sacramentorum celebrationem» (cfr. R. RYBAK, $L a$ visita «ad limina apostolorum»..., cit.).

47 En un sentido más general, Lüdecke atribuye una garantía de integridad y calidad como la que señalamos en el texto, en toda concesión de missio canonica (independientemente de que consista o no en actos de potestad); cfr. N. LÜDECKE, «Missio canonica», en Diccionario general de derecho canónico, V, Instituto Martín de Azpilcueta, Pamplona 2012, 440. 
reclama un ulterior elemento de prudencia en la provisión de un oficio capital y por ende en el reconocimiento de la comunión jerárquica del sujeto que es nombrado. Si es que es posible hablar así, no sólo «cuantitativamente» sino «cualitativamente», ser consolidado en la comunión al ser incorporado al colegio y entrando en una posición de capitalidad episcopal concede un fundamental «crédito de comunión» que tiene un importante valor tanto para las funciones del oficio como para las colectivas, como parte del colegio.

En consecuencia, es claro que la acreditación de la comunión jerárquica en fase de provisión del oficio capital no es un expediente meramente formal o estático, sino precisamente una garantía consciente y responsable erga omnes de participación en esos bienes en que se basan los vínculos de la comunión. Unos vínculos que atestiguan una comunión no sólo con el Romano Pontífice sino precisamente con él y con el resto del colegio episcopal: no en vano, además de la efectiva comunión con el Romano Pontífice, que en el momento inicial que estamos considerando es bien concreta, en la realidad de las cosas ésta, sin absorberla, simboliza o representa la comunión efectiva con los miembros del colegio ${ }^{48}$.

El c. 1013 CIC explicita que «a ningún Obispo le es lícito conferir la ordenación episcopal sin que conste previamente el mandato pontificio». En este canon gravitan importantes cuestiones relativas tanto a la celebración del sacramento del orden como a la concesión de la comunión jerárquica ${ }^{49}$, liga-

48 Se trata de una cuestión relevante en la valoración de la real comunión en el colegio: en efecto, esta comunión con el colegio (casi) se puede considerar presunta cuando concurre la comunión efectiva con la Cabeza del colegio: razón de más para que la comunión con el Papa sea realmente efectiva. No se puede considerar superficialmente la comunión otorgada por el Papa como una mera acción voluntarista de poder: independientemente de que haya escasos medios establecidos que permitan cuestionar esa acción una vez realizada o que puedan en ocasiones prevalecer importantes cuestiones de prudencia de gobierno para no hacerlo valer, esa acción como acto de prudencia jurídica se funda en datos ciertos y veraces que acreditan que esa persona verdaderamente se halla en comunión y está en condiciones de conservarla y promoverla. Conservación y promoción que es llamada a realizar tanto a nivel universal y en relación a la propia circunscripción eclesiástica, como asimismo en otros niveles relacionales, como por ejemplo en el ámbito de un concilio particular o una conferencia episcopal (sobre el carácter análogo de la comunión, su referencia a la Cabeza del colegio, y su irreductibilidad a un reparto de poderes, cfr. C. J. ERrázURIZ M., Corso fondamentale..., cit., nn. 127, 129, 131). En este sentido puede afirmarse que la línea de provisión de oficios episcopales que se sigue en cada periodo histórico da lugar a una opción por una determinada configuración de los vínculos de la comunión.

49 Este canon conserva la misma redacción del precedente de CIC-1917, salvo el primer sintagma que enunciaba su justificación (c. 953 CIC-1917: «Consecratio episcopalis reservatur Romano Pontifici ita ut nulli Episcopo liceat quemquam consecrare in Episcopum, nisi prius constet de pontificio mandato»). La omisión es relevante: si se observa la historia redaccional del canon del 
dos a la dilucidación de las relaciones entre potestad de orden y potestad de jurisdicción ${ }^{50}$.

Es claro que, en condiciones normales, el régimen actual del nombramiento de obispos en la Iglesia latina (c. $377 \$ 1$ CIC) atribuye al Papa el «acto (...) que contiene la legitimación para recibir la consagración episcopal de las manos de un obispo» ${ }^{51}$ (en esto consiste el llamado mandato pontificio). Aunque las consecuencias penales de la contravención de tal exigencia son inequívocas (c. $1382 \mathrm{CIC}$ ), no se puede desconocer que existe un gobierno, y en consecuencia una acción prudencial, ligado a la concesión del mandato pontificio cuando está en juego la continuidad de la comunión eclesial ${ }^{52}$.

código piobenedictino (cfr. Z. TRACZ, La facultad pontificia de consagrar obispos y su protección penal en la legislación anterior al código de derecho canónico de 1917, Ius Canonicum 84 [2002] 629-662), es evidente la conmixtión de cuestiones relativas a la provisión del oficio episcopal en sentido estricto y las que se referían a la reserva pontificia de la consagración u ordenación episcopal. La historia redaccional del canon del vigente CIC se mueve en coordenadas bien diversas como son las determinadas por la doctrina del Concilio Vaticano II sobre el episcopado (cfr. Communicationes 10 [1978] 182-183), incluida la suspensión del juicio contenida en la N. B. de la Nota explicativa previa de la LG: «Sin la comunión jerárquica no puede ejercerse el ministerio sacramental-ontológico, que debe distinguirse del aspecto canónico-jurídico. Sin embargo, la Comisión ha juzgado que no debía ocuparse de las cuestiones acerca de la licitud y la validez, que se dejan a la discusión de los teólogos».

${ }^{50}$ Cfr. Z. TracZ, «Mandato pontificio», en Diccionario general de derecho canónico, V, Instituto Martín de Azpilcueta, Pamplona 2012, 266-268.

${ }^{51}$ Ibid., 266.

52 A la orden del día se encuentran los casos extraordinariamente complejos en relación a los cuales desde hace bastantes años la Sede apostólica se expresa en un modo que, al margen de las eventuales sanciones penales (cfr. Pontificio Consiglio Per i Testi Legislativi, Dichiarazione sulla retta applicazione del canone 1382 del Codice di Diritto Canonico [6-VI-2011], L'Osservatore Romano de 6 de junio de 2011, 7), sin entrar en la cuestión de la validez o no de la ordenación, quiere ser clara a propósito del «no reconocimiento» y de la ausencia de autoridad de gobierno pretendidamente obtenido por el candidato ordenado sin mandato pontificio: cfr. SACRA CONGREGAZIONE PER La DotTRINA DELla FeDE, Notificazione con la quale si dichiarano di nuovo le pene canoniche incorse dall'Arcivescovo Pierre-Martin Ngô-dińh-Thuc e complici per le ordinazioni illecite di presbiteri e vescovi (12-III-1983), AAS 75 (1983) 392-393; precedentemente se había expresado en modo análogo, cfr. Decretum circa quasdam illegitimas ordinationes presbyterales et episcopales (17-IX-1976), AAS 68 (1976) 623. Recientemente, a propósito de la situación de China, aunque las circunstancias son muy diferentes de las del caso reseñado, la formulación es análoga: «la Santa Sede non lo riconosce come Vescovo dell'amministrazione apostolica di Harbin, ed egli è privo dell'autorità di governare i sacerdoti e la comunità cattolica nella provincia di Heilongjiang» (Dichiarazione della Santa Sede sulle ordinazioni episcopali ad Harbin e a Shanghai [10-VII-2012], www.vatican.va). A propósito de las consecuencias penales de una ordenación sin mandato, en este campo se observa con claridad la interacción entre derecho y gobierno (con las graves implicaciones a nivel sacramental), y las soluciones que se intenta encontrar para que el bien de la continuidad de la Iglesia en la comunión universal sea compatibilizado con el acceso a los bienes salvíficos por parte de los fieles, de modo que no cristalicen 
Específico de la ordenación episcopal en relación a otros grados del orden es la forma propia de administración del sacramento del orden en su grado supremo, que explicita la autenticidad de los bienes implicados en la condición episcopal, y que éstas sean socialmente reconocibles: la sucesión apostólica y los dones personales. La sucesión apostólica es manifestada a través de signos inequívocos de valor sacramental como la acogida en el ministerio por un obispo que ordena con la presencia activa de al menos otros dos obispos en la ordenación (c. 1014 CIC), o la constancia a nivel litúrgico del mandato pontificio ${ }^{53}$ (c. 1013 CIC) expresivo de una acción de la Cabeza del colegio.

\section{LA DIMENSIÓN DE MODERACIÓN DEL MINISTERIO EPISCOPAL: ENTRE DERECHO Y GOBIERNO}

Hasta el momento hemos prestado atención a las exigencias jurídicas vinculadas con la recepción del sacramento del orden y a la acreditación de la comunión jerárquica. Como veíamos al inicio de estas páginas, tales exigencias no se deben separar excesivamente de las que corresponden al oficio episcopal del caso concreto: es poco realista considerar que en primer lugar se acredita la idoneidad para ser obispo y en un segundo momento se efectúa la valoración acerca de las condiciones para un oficio episcopal concreto. El sistema vigente se articula en una serie de requisitos, que hemos examinado en líneas precedentes, y en unos procedimientos (sintetizados en el c. 377 CIC). Sería asimismo simplista considerar que los requisitos aluden a la dimensión universal del ministerio y los procedimientos permiten aquilatar las circunstan-

\footnotetext{
de modo irreversible situaciones nacidas en un contexto de falta de libertad. No se puede perder de vista la esperanza fundada en el hecho de que el episcopado y consecuentemente la sucesión apostólica atraen hacia la unidad. Junto con expresiones históricas bien concretas, debe entenderse que los esfuerzos eclesiales por combatir la consolidación de situaciones de falta de comunión alcancen hasta la tolerancia con acciones sacramentales que aun siendo gravemente ilegítimas pueden ser sanadas.

53 El Pontificale Romanum prevé la constancia del mandato por medio de un diálogo entre un presbítero y el ordenante principal, y un asentimiento de los presentes: «Reverendíssime Pater, póstulat Ecclésia N., ut presbyterum N. ad onus Episcopátus órdines» (cuando el obispo no es residencial la fórmula es: «Reverendíssime Pater, póstulat sancta Mater Ecclesia catholica, ut presbyterum N. ad onus Episcopátus órdines»); «Habétis mandatum Apostólicum?»; «Habémus»; «Legátur»; se lee el mandato y, una vez concluida la lectura, todos los presentes asienten (cfr. De ordinatione episcopi, presbyterorum et diaconorum, Typis Polyglottis Vaticanis, Città del Vaticano 1990, n. 38). En rigor, la cuestión relevante es la constancia del mandato (c. 1013 CIC), que puede obtenerse por diferentes vías, incluso sin la efectiva posesión del documento oficial que lo testimonia (cfr. Z. TraCZ, Mandato pontificio, cit., 266-267).
} 
cias del oficio concreto, la dimensión particular del ministerio. No es así: también los requisitos para la recepción del sacramento y la acreditación de la comunión jerárquica son objeto de atención en los procedimientos ${ }^{54}$. Es cierto, sin embargo, que los procedimientos se focalizan en la idoneidad para el episcopado en principio en la perspectiva local, y en este nivel -con distintas modalidades según los diferentes procedimientos- prevalece la intención de identificar la persona más adecuada para el oficio concreto. Ante la inconveniencia e imposibilidad de que aspectos tan particulares se fijen en unas reglas generales, la solución ideada es la del procedimiento, al que sigue una atenta evaluación de informaciones y preferencias que tiende a garantizar un buen gobierno del nombramiento de los obispos.

Como hemos señalado, nos ocupamos de las dinámicas internas a estos procedimientos en otro trabajo. Con todo, no nos parece que con la consideración de los requisitos de idoneidad de la persona y los procedimientos para conocerlos y fundar razonablemente el acto de provisión en sentido estricto quede sustanciada la temática de la provisión del oficio capital.

En efecto, se puede identificar un contexto intermedio entre las exigencias universales y las exigencias del oficio, que influye también en la provisión de oficios capitales. Se trata de lo que podríamos denominar la dimensión de «moderación del ministerio episcopal». Esta dimensión ofrece por lo menos dos facetas.

${ }^{54}$ Basta considerar que el «Cuestionario» contiene preguntas (que se dirigen a un buen número de personas) que responden a la idoneidad para la ordenación episcopal y para aquilatar la comunión jerárquica. Ya hemos considerado las exigencias de fe firme y disciplina; añádase que a los que responden al cuestionario se les pregunta explícitamente por las cualidades humanas y sobrenaturales del posible candidato y por su «idoneidad para el episcopado» (cfr. T. J. REESE, The Selection of Bishops, cit.). Por otro lado, ya que los procedimientos conducen a tomar una decisión que corresponde a la Sede apostólica y en último lugar al Papa, todos ellos están marcados por las directrices que existen a tal propósito. Es obvio que los colaboradores del Papa (en todos los niveles, pero especialmente en la fase romana de la decisión) no son meros gestores neutrales de la información que reciben. El mismo Papa da las directrices que considere justas, y que espera que se tendrán en cuenta en los procedimientos. Lo puede hacer de forma implícita, al proporcionar orientación sobre las necesidades de los fieles y sobre la misión pastoral del episcopado en los documentos oficiales promulgados para este fin, en las directrices dadas en las sesiones plenarias de las congregaciones competentes o durante las audiencias en las que proporciona recomendaciones para este sector del gobierno de la Iglesia. Han sido muy significativos y explícitos los discursos del Papa Francisco en la Audiencia a los participantes en las «Jornadas de representantes pontificios» con ocasión del año de la fe (21-VI-2013), en la Reunión de la Congregación para los obispos (27-II-2014), y en la Audiencia a los participantes en el Encuentro de representantes pontificios, con ocasión del Jubileo de la Misericordia (17-IX-2016). 
Una primera faceta incluye una serie de cuestiones acerca del gobierno «sobre» los obispos, no tanto desde el punto de vista de sus funciones episcopales, constitutivas de la dimensión institucional de la misión episcopal (aquello en lo que el ejercicio de sus funciones reclame relaciones con otras instancias supradiocesanas o centrales) como desde el punto de vista de su autonomía personal, la tutela de su posición capital y la vigilancia sobre su actuación; en definitiva, lo que se podría denominar el aspecto disciplinar de la misión episcopal. Una segunda faceta consiste en las relaciones existentes entre los obispos de un cierto ámbito, generalmente nacional, no tanto en su dimensión institucional organizativa (que se refiere a las funciones ejercitadas en cooperación, sobre todo en la conferencia episcopal) como en su dimensión social, relacional: el conjunto de personas y relaciones que de forma poco precisa a veces se denomina «el episcopado» de un país o de una región, tanto en las relaciones de los pastores entre ellos como con el entorno eclesial y sociopolítico.

En relación a la primera de las facetas de esta dimensión hay que considerar que la misión episcopal del oficio capital delinea una figura fuertemente gravada con responsabilidades pastorales y a la vez notablemente autónoma.

En efecto, una parte importante de las funciones que se deben desplegar supone un amplio margen de capacidad de decisión y de responsabilidad de gobierno, que se debe afrontar en primera persona (cc. 381, $391 \$ 2,480$ CIC) $\mathrm{y}$ aun en ocasiones a título personalísimo ${ }^{55}$. Ciertamente el ordenamiento canónico establece la obligatoria constitución de oficios y colegios destinados a auxiliar al obispo, así como supuestos en los que el obispo debe contar con el parecer y aun con el consenso de alguna de esas instancias; también en algunos casos debe contar con la intervención de la Sede apostólica. No obstante

${ }^{55}$ No nos referimos solamente a aquellas competencias que el c. $134 \$ 3$ CIC sintetiza como propias del obispo diocesano (o equiparados) y que otras instancias podrían ejercitar sólo mediando un mandato especial. Se trata de la delimitación de la responsabilidad del obispo, cuyos perfiles han aumentado en complejidad en los últimos años y que en algunos contextos, como el económico y algunos aspectos del penal se hallan en fase de esclarecimiento (cfr. el asunto tratado en Pontificio Consiglio per i Testi Legislativi, Elementi per configurare l'ambito di responsabilità canonica del Vescovo diocesano nei riguardi dei presbiteri incardinati nella propria diocesi e che esercitano nella medesima il loro ministero, Communicationes 36 [2004] 33-38). Cfr. R. J. KASLYN, Accountability of Diocesan Bishops. A Significant Aspect of Ecclesial Communion, The Jurist 67 (2007) 109-152, que ofrece una panorámica de temas sobre la base de la tesis central según la cual «la responsabilidad [así traducimos la expresión más técnica de accountability] es un elemento integral de la estructura de la Iglesia y es esencial en el oficio de obispo» (109). 
estas cautelas, en su conjunto en relación al oficio episcopal se dibuja una figura de gobierno notablemente personalizada ${ }^{56}$.

Tal posición, por otro lado, se halla vinculada a la duración indeterminada de los nombramientos episcopales diocesanos, con la única certeza de un deber de presentar la renuncia a los 75 años (c. $401 \$ 1$ CIC). Además, se presupone una tendencial estabilidad en la sede, ya que los traslados por causa de dificultades del titular en el gobierno, aunque posibles, son muy limitados y con frecuencia contraproducentes, y las renuncias o remociones suelen estar ligadas a causas graves (c. $401 \$ 2 \mathrm{CIC})^{57}$.

Esta posición personalizada, autónoma y estable, fundada en la condición de vicario de Cristo y en la posición constitucionalmente originaria del obispo diocesano (LG 27), merece ser oportunamente protegida. En efecto, en el interés de la Iglesia se arbitran medios para robustecer y tutelar esa posición institucional, a la vez que se hace lo posible para minimizar el daño a los bienes eclesiales y los titulares de derechos en relación a ellos, que se puedan producir en razón de errores o límites humanos de quien la ejerce.

Por estas razones, el acceso a la condición episcopal inserta a la persona en un contexto de tutela y responsabilidad por medio de unos sistemas de control y verificación de la actividad del obispo. Éstos se concretan en la sujeción

${ }^{56}$ Cfr. J. Herranz, La funzione di governo del vescovo diocesano, en Giustizia e pastoralità nella missione della Chiesa, A. Giuffrè, Milano 2011, 316-317. Una afirmación de Bier, conclusiva de su importante trabajo sobre el obispo diocesano, ha despertado un cierto malestar que a su vez ha sido encauzado hacia el deseo de una mejor colaboración entre derecho canónico y teología. Bier afirma: «según la determinación general del código en la materia del episcopado, el obispo diocesano y la configuración normativa de su ministerio en él describe al obispo diocesano como un funcionario del papa» (G. BIER, Die Rechtsstellung des Diözesanbischofs..., cit., 376). Legrand califica de irritante (irksome) esta tesis «ya que, si bien el autor tiene razón en el nivel del derecho vigente, nunca se refiere a cómo la ley se distancia equivocadamente de la teología» (H. LEGRAND, The Bishop Is in the Church and the Church Is in the Bishop. Research Is Still Required in Catholic Ecclesiology, The Jurist 66 [2006] 79; entra en el mismo debate M. WIJLENS, Bishops and their relationship to a local Church: a canonical perspective, The Jurist 66 [2006] 211-241). La cuestión nos aleja del tema que estamos tratando pero a la vez pone de relieve la necesidad de una mayor investigación no sólo en la eclesiología, sino también en derecho canónico, para colmar las disonancias que aún se producen entre estas dos perspectivas para considerar la misma realidad.

57 En tiempos recientes la Sede apostólica se ha ocupado de esta cuestión, de perfiles complejos, especialmente por lo que se refiere a los casos en que media un juicio sobre la diligencia del obispo. Cfr. FranCISCO, Rescripto «ex audientia Ss.mi» con Disposizioni sulla rinuncia dei Vescovi diocesani e dei titolari di uffici di nomina pontificia (5-XI-2014), AAS 106 (2014) 882-884; FRANCISCO, Carta Apostólica en forma de «motu proprio» Come una madre amorevole (4-VI-2016), L'Osservatore Romano de 4 de junio de 2016, 3 (cfr. nuestro comentario a este documento La responsabilità giuridica dell'autorità ecclesiastica per negligenza in un deciso orientamento normativo, Ius Ecclesiae 38 [2016] 718-734). 
a concretas autoridades, ámbitos de rendición de cuentas de su actividad, derechos y deberes ligados a la condición episcopal, esferas de especial protección eclesial y aun civil, responsabilidades especiales, etc. Situaciones jurídicas, todas ellas, que son complementarias de la carga de funciones propias como miembro del colegio episcopal o del oficio, y se hallan destinadas a tutelar a la persona que las ejerce, el valor eclesial de las funciones que se ejercen e indirectamente a los beneficiarios de tal actividad ${ }^{58}$.

Esta función de tutela y de exigencia de responsabilidad recae principalmente en la Sede apostólica. En parte esta dependencia se debe a la extinción o novación del precedente vínculo de incardinación del presbítero llamado al episcopado. No ciertamente al aspecto de destinación al servicio propio de la incardinación, que se ha transformado en servicio al ministerio episcopal y a la circunscripción de cuyo oficio capital se es titular, y tampoco a ciertas cuestiones, como las de tipo retributivo o en general a la atención de las necesidades más personales del obispo que recaen en la circunscripción ${ }^{59}$. Esa dependencia específica se refiere a los bienes que se protegen con las normas canónicas y con las que en su caso el derecho eclesiástico establece según el sistema de relaciones con las instancias estatales ${ }^{60}$.

Necesariamente hay que hacer referencia a la dependencia del obispo por lo que se refiere a medidas sancionatorias, administrativas o penales, en rela-

${ }^{58}$ Cfr. J. I. ARrieta, Diritto dell'organizzazione..., cit., 377-378; A. ViAna, Organización del gobierno en la Iglesia, Eunsa, Pamplona 2010, 78-80.

59 En estos dos ámbitos referidos continúa la dependencia respecto de la circunscripción, pero es obvio que cambia el tipo de vinculación: mientras la incardinación supone un régimen de subordinación común y bajo la supervisión del obispo, cuando se trata del obispo mismo decide personalmente sobre esas prestaciones. Valgan como ejemplo las directivas del Directorio Apostolorum successores que apuntan al debido equilibrio entre pobreza y dignidad en la vida personal: «Por tanto, deberá ser y aparecer pobre, será incansablemente generoso en la limosna y llevará una vida modesta que, sin quitar dignidad a su oficio, tenga sin embargo en cuenta las condiciones socioeconómicas de sus hijos. Como exhorta el Concilio, trate de evitar todo lo que pueda de cualquier modo inducir a los pobres a alejarse, y aún más que los otros discípulos del Señor, trate de eliminar en las propias cosas toda sombra de vanidad. Disponga la propia habitación de manera tal que ninguno pueda juzgarla inaccesible, ni deba, incluso si es de humilde condición, encontrarse en ella a disgusto» (n. 45). El contenido moral de estas indicaciones no elimina un eventual elemento de responsabilidad jurídica, en el caso en que se pudiera acreditar un uso desviado de recursos.

${ }^{60}$ Las fórmulas y las cuestiones pueden ser muy variadas; desde eventuales atribuciones garantizadas por el Estado (status especial, privilegios, prerrogativas) a situaciones más o menos consolidadas de marginación o de hostilidad en relación a la Iglesia y a sus ministros. Junto a las garantías que la Sede apostólica puede reclamar en su caso a los estados en el ámbito internacional, debe tenerse en cuenta la realidad de hecho que la representación institucional del obispo, en la región y aun en el país, le convierte en un sujeto de cierta trascendencia pública. 
ción a las cuales es situado en inmediata dependencia de otras instancias, generalmente episcopales: en parte para algunas cuestiones los obispos metropolitanos (cfr. cc. 436; $395 \$ 4 ; 415$ CIC) y, habitualmente por medio de los legados pontificios (c. 364 CIC), sobre todo la Sede apostólica, a través de la correspondiente congregación romana según la circunscripción (arts. 58, 75, $89 \mathrm{~PB})$ o en ocasiones según la especial materia o la gravedad del asunto ${ }^{61}$.

Vista desde la perspectiva de la autoridad -y con mayor razón del pueblo fiel que reclama un pastor adecuado a sus necesidades- una elección desafortunada por la falta de la debida diligencia en quienes intervienen en ella puede causar daños que no se remedian fácilmente. Dejando de lado los que se pueden ocasionar en forma de escándalo cuando fuere el caso, es difícil evaluar los que derivan de la actividad o la inactividad de quien viene a demostrarse que carecía de las condiciones de un buen pastor para una circunscripción. Ninguna de estas consideraciones puede ser pasada por alto en fase de provisión de oficios episcopales, precisamente en vista a la protección de bienes eclesiales de los que se hacen funcionalmente y personalmente garantes los titulares de los oficios capitales. Es obvio que en lo que pueda ser verificado al inicio del ministerio, estas cuestiones pueden y deben condicionar el nombramiento de una persona.

En relación a la segunda faceta de esta dimensión de moderación del ministerio episcopal, la que se refiere a relaciones que se establecen en el «episcopado local», es natural que la provisión de los oficios episcopales la tenga en consideración.

No nos referimos de modo exclusivo a las relaciones jurídicas que se establecen entre los obispos en instancias, institucionalizadas o no, que entran en el contexto del ejercicio de las funciones episcopales en sus formas personales o colectivas ${ }^{62}$. Se trata más bien de las que se establecen de modo generalmente informal como respuesta a las problemáticas locales, tanto eclesiales

${ }^{61}$ Cfr. art. $1 \$ 2$ Normae de delictis Congregationi pro Doctrina Fidei reservatis seu Normae de delictis contra fidem necnon de gravioribus delictis (21-V-2010), AAS 102 (2010) 419-434: «En los delitos de los que se trata en el $\$ 1$, por mandato del Romano Pontífice, la Congregación para la Doctrina de la Fe tiene el derecho de juzgar a los Padres Cardenales, a los Patriarcas, a los legados de la Sede Apostólica, a los Obispos (...)».

${ }^{62}$ Cfr. L. NAVARRO, Il vincolo di comunione episcopale e le sue manifestazioni giuridiche, en ConsociaTIO INTERNATIONALIS STUDIO IURIS CANONICI PROMOVENDO (ed.), La synodalitè. La participation au gouvernement dans l'Église, vol. I, L'Anne canonique, Paris 1992, 212-215. En este trabajo se apunta a la dimensión jurídica y no sólo moral de una buena parte de las relaciones entre los obispos precisamente en virtud de la común pertenencia al ordo episcoporum. 
como civiles. Estas respuestas pueden tener efectos variados; con frecuencia conducen a una mayor unidad y cohesión en el episcopado, pero otras veces pueden llevar a la formación de sectores a propósito de determinados temas, $\mathrm{o}$ incluso a una fragmentación o aun a un enfrentamiento de las posiciones. El equilibrio y la promoción de la unidad del episcopado no es ajena a los criterios de nombramiento de obispos.

Un presupuesto de estas cuestiones, que sólo enunciamos en cuanto influye en ellas, es la delimitación del área de influjo común del episcopado, el número de circunscripciones que la componen y su mayor o menor homogeneidad $^{63}$, así como el número de obispos auxiliares que, junto con los obispos titulares de oficios capitales, prestan su ministerio en tal zona. Con frecuencia los nombramientos episcopales responden a perspectivas de cobertura de más de una sede, con una proyección temporal que tiende a prever eventuales traslados hacia oficios capitales más complejos ${ }^{64}$.

La atención a esta dimensión local del episcopado, no circunscrita al oficio singular, manifiesta como con frecuencia la selección y el nombramiento de obispos se enfoca como una operación de cooptación entre los actuales miembros del episcopado y algunos sacerdotes que han entrado en los procedimientos de selección iniciales ${ }^{65}$. Es también cierto que la dimensión universal del episcopado y la perspectiva también universal de la Sede apostólica hacen posible, y a veces conveniente, el nombramiento como obispo de una persona que se encuentra fuera del entorno local actual, pero con frecuencia

${ }^{63}$ Sobre esta cuestión, que se enfoca desde el punto de vista de la racionalización de los recursos disponibles y las necesidades del Pueblo de Dios, más que desde el de los pastores, cfr. CD, nn. 22-24; Paulus VI, M. P. Ecclesiae Sanctae (6-VIII-1966), AAS 58 (1966) I, n. 12. Quizás el caso aplicativo más conocido ha sido el de la reordenación de las diócesis en Italia, ligada también al Accordo di revisione del Concordato Lateranense stipulato tra la Santa Sede e il Governo italiano (SACra Congregatio Pro EPIsCopis, Prot. N. 971/85, 30 de septiembre de 1986).

${ }^{64}$ No nos compete valorar el grado de justificación y los efectos de tal proceder; baste señalar que se halla implícito en los nombramientos, que es un modo -no necesariamente el único- de generar un elemento fundamental en vista al gobierno de las sedes más grandes (y no infrecuentemente más problemáticas) como es la experiencia acumulada y que, aun sin generar derechos, inevitablemente crea expectativas y en ocasiones indebidas aspiraciones. Cfr. A. VIANA, Obispos titulares: elementos de tradición canónica y regulación actual, Ius Canonicum 88 (2004) 515-537; H. LEGRAND, Il primato romano, la comunione tra le Chiese e la comunione dei vescovi, Concilium 49 (2013) 90-109. Ejemplificativo en este sentido el estudio relativo al episcopado de los Estados Unidos; cfr. J. M. RITTY - J. A. CORIDEN, Report to the CLSA Membership on the Selection of Bishops, Proceedings of the Canon Law Society of America (2002) 334-360.

${ }^{65}$ Cfr. G. Trevisan, Le buone qualità del candidato all'episcopato, Quaderni di Diritto Ecclesiale 1 (1999) 69. 
la cuestión de los nombramientos episcopales se resuelve barajando un número limitado de sedes y de personas en un ámbito territorial delimitado.

En este contexto adquiere una especial relevancia el aspecto del episcopado, que lo pone en relación con instancias externas al gobierno estrictamente diocesano, como son las relaciones ecuménicas y, en otro orden de cosas, aquellas que se refieren a otras instancias sociales, políticas, culturales o económicas. Aunque con diferentes modalidades según los lugares, el episcopado (y a veces el obispo de una sede determinada) es llamado a desplegar un papel de interlocutor en las relaciones ecuménicas, o, por la relevancia de los cristianos o católicos en un determinado contexto, incluso de actor en la esfera pública civil.

En todo caso, es claro que se verifican líneas de convergencia en dependencia de factores de diverso género, que conducen a una política de nombramientos episcopales que tiene en cuenta esos factores, para equilibrarlos si se dan tensiones o posiciones encontradas, para promover especialmente la cohesión o para alcanzar otras finalidades derivadas de las relaciones reales o futuras entre los miembros de ese episcopado. Las cuestiones pueden ser muy variadas y no nos compete entrar a valorarlas; nos basta señalar que estos elementos forman parte del buen gobierno del ministerio episcopal y no es indiferente a la provisión de los oficios episcopales. 


\section{Bibliografía}

AMENTA, P., La dichiarazione di nullità dell'ordinazione sacerdotale, en GRUPPO ITALIANO DOCENTI DI DIRITTO CANONICO (ed.), Il diritto nel mistero della Chiesa (IV). Prassi amministrativa e procedure speciali, Lateran University Press, Roma 2014, 349-364.

Arrieta, J. I., Diritto dell'organizzazione ecclesiastica, A. Giuffrè, Milano 1997.

Aymans, W. - MöRsdorf, K., Kanonisches Recht. Lebrbuch aufgrund des Codex iuris canonici, vol. II, F. Schöningh, Paderborn [etc.] 1997.

Bernal, J., «Excomunión», en J. Otaduy - A. Viana - J. Sedano (eds.), Diccionario general de derecho canónico, III, Thomson Reuters Aranzadi, Cizur Menor (Navarra) 2012, 835-840.

Bertrams, W., De differentia inter sacerdotium episcoporum et presbyterorum, Periodica 59 (1970) 185-213.

BIER, G., Die Rechtsstellung des Diözesanbischofs nach dem Codex iuris canonici von 1983, Echter, Würzburg 2001.

BRAIDA, P. V. A., Elezione e nomina dei vescovi in Svizzera, en D. J. ANDRÉs GUTIÉRREZ (ed.), Il processo di designazione dei vescovi. Storia, legislazione, prassi, PUL editrice, Città del Vaticano 1996, 533-559.

Brogi, M., Elezione dei Vescovi Orientali Cattolici, en D. J. ANDrÉs GuTIÉRreZ (ed.), Il processo di designazione dei vescovi: storia, legislazione, prassi, PUL editrice, Città del Vaticano 1996, 567-613.

CARON, P. G., La rinuncia all'ufficio ecclesiastico nella storia del diritto canonico dalla età apostolica alla riforma cattolica, Vita e pensiero, Milano 1946.

De Paolis, V., Nota sul titolo di consacrazione episcopale, Ius Ecclesiae 14 (2002) 59-79.

EJEH, B., The principle of suitability in the provision of ecclesiastical offices in the 1983 Code of Canon Law, Ius Ecclesiae 20 (2008) 569-591.

Errázuriz M., C. J., Corso fondamentale sul diritto nella Chiesa, vol. I, A. Giuffrè, Milano 2009.

Fabene, F., «Provisión de las sedes episcopales», en J. OtaduY - A. Viana J. Sedano (eds.), Diccionario general de derecho canónico, VI, Thomson Reuters Aranzadi, Cizur Menor (Navarra) 2012, 619-621.

GänsweIn, G., «I vescovi ... sono autentici dottori e maestri della fede». Annotazioni sulla genesi e l'interpretazione del can. 753 CIC, Ius Ecclesiae 14 (2002) 135-155. 
GHIRLANDA, G., «Comunione ecclesiale/ecclesiastica/gerarchica», en C. CoRRAL - V. DE PAOlis - G. GhirLANDA (eds.), Nuovo dizionario di diritto canonico, Edizioni Paoline, Milano 1993, 209-214.

Gómez-Iglesias C., V., Circa l'elevazione all'Episcopato del secondo Prelato dell'Opus Dei, Ius Ecclesiae 7 (1995) 799-801.

—, L'Ordinazione episcopale del Prelato dell'Opus Dei, Ius Ecclesiae 3 (1991) 251-265.

González Gaitano, N., Public opinion and the Catholic Church. A theoretical perspective, en Public opinion and the Catholic Church, Edusc, Roma 2010, $9-47$.

GreEn, T. J., Particular Churches and their groupings (cc. 368-572), en T. J. Green - D. E. Heintschel - J. A. Coriden - Canon LaW Society of America (eds.), The code of canon law: a text and commentary, G. ChapmanPaulist Press, London-New York 1985, 311-349.

GrEshaKe, G., Bischofsernennungen im Lichte einer Theologie des kirchlichen Amtes und einer Communio-Ekklesiologie, en G. GRESHAKE (ed.), Zur Frage der Bischofsernennungen in der römisch-katholischen Kirche, Schnell \& Steiner, München 1991, 104-139.

Heimerl, H. - PreE, H., Kirchenrecht. Allgemeine Normen und Eherecht, Springer, Wien-New York 1983.

HERRANZ, J., La funzione di governo del vescovo diocesano, en Giustizia e pastoralità nella missione della Chiesa, A. Giuffrè, Milano 2011, 311-340.

Hervada, J., Elementos de derecho constitucional canónico, Eunsa, Pamplona 2001.

Kaslyn, R. J., Accountability of Diocesan Bishops. A Significant Aspect of Ecclesial Communion, The Jurist 67 (2007) 109-152.

LÉCUYER, J., L'episcopato come sacramento, en BARAúNA, G. (ed.), La Chiesa del Vaticano II. Studi e commenti intorno alla costituzione dommatica «Lumen gentium», Vallecchi, Firenze 1965, 713-732.

—, Le sacrement de l'ordination: recherche historique et théologique, G. Beauchesne, Paris 1983.

Legrand, H., The Bishop Is in the Church and the Church Is in the Bishop. Research Is Still Required in Catholic Ecclesiology, The Jurist 66 (2006) 70-92.

-, Il primato romano, la comunione tra le Chiese e la comunione dei vescovi, Concilium 49 (2013) 90-109.

LORUsso, L., La designazione dei vescovi nel Codex canonum ecclesiarum orientalium, Quaderni di Diritto Ecclesiale 12 (1999) 46-57. 
LÜdecke, N., «Missio canonica», en J. Otaduy - A. Viana - J. Sedano (eds.), Diccionario general de derecho canónico, V, Thomson Reuters Aranzadi, Cizur Menor (Navarra) 2012, 437-441.

Marzoa, Á. - Miras, J. - Rodríguez-Ocaña, R. (eds.), Comentario exegético al Código de derecho canónico, Eunsa, Pamplona 1996.

Migliavacca, A., «Idoneidad para oficios y ministerios», en J. OtadUY - A. Viana - J. Sedano (eds.), Diccionario general de derecho canónico, IV, Thomson Reuters Aranzadi, Cizur Menor (Navarra) 2012, 361-365.

MiÑambres, J., Concorso di diritti nelle provviste canoniche, Ius Ecclesiae 7 (1995) 115-130.

—, La presentazione canonica. Collaborazione nella provvista degli uffici ecclesiastici, A. Giuffrè, Milano 2000.

Mosca, V., La perdita della condizione giuridica clericale e il procedimento di dispensa dei suoi obblighi, en GRUPPO ITALIANO DOCENTI DI DIRITTO CANONICO (ed.), Il diritto nel mistero della Chiesa (IV). Prassi amministrativa e procedure speciali, Lateran University Press, Roma 2014, 365-388.

NAVARRO, L., Il vincolo di comunione episcopale e le sue manifestazioni giuridiche, en CONSOCIATIO INTERNATIONALIS STUDIO IURIS CANONICI PROMOVENDO (ed.), La synodalitè. La participation au gouvernement dans l'Église, vol. I, L'Anne canonique, Paris 1992, 205-215.

Primetshofer, B., La nomina dei vescovi nell'Austria, Germania e Svizzera, en D. J. ANDRÉs GUTIÉRREZ (ed.), Il processo di designazione dei vescovi. Storia, legislazione, prassi, PUL editrice, Città del Vaticano 1996, 511-539.

RAHNER, K., Strukturwandel der Kirche als Aufgabe und Chance, Herder, Freiburg im Breisgau-Basel-Wien 1972.

ReESE, T. J., The Selection of Bishops, America Magazine, Aug. 18 (1984).

RINCÓN-PÉREZ, T., El orden de los clérigos o ministros sagrados. Formación, incardinación y estatuto jurídico personal, Eunsa, Pamplona 2009.

Ritty, J. M. - Coriden, J. A., Report to the CLSA Membership on the Selection of Bishops, Proceedings of the Canon Law Society of America (2002) 334-360.

RYBAK, R., La visita «ad limina apostolorum» nei documenti della Santa Sede e nel Codice di diritto canonico del 1983, Pontificia Università Lateranense, Romae 1994.

Sabbarese, L., «Provisión del oficio», en J. Otaduy - A. Viana - J. Sedano (eds.), Diccionario general de derecho canónico, VI, Thomson Reuters Aranzadi, Cizur Menor (Navarra) 2012, 621-624. 
SHAW, R. B., Notbing to bide: secrecy, communication and communion in the Catholic Church, Ignatius Press, San Francisco (CA) 2008.

TkhorovskyY, M., Procedura per la nomina dei vescovi: evoluzione dal Codice del 1917 al Codice del 1983, Pontificia Università Gregoriana, Roma 2004.

TRACZ, Z., La facultad pontificia de consagrar obispos y su protección penal en la legislación anterior al código de derecho canónico de 1917, Ius Canonicum 84 (2002) 629-662.

-, «Mandato pontificio», en J. Otaduy - A. Viana - J. SEdano (eds.), Diccionario general de derecho canónico, V, Thomson Reuters Aranzadi, Cizur Menor (Navarra) 2012, 266-268.

Trevisan, G., Le buone qualità del candidato all'episcopato, Quaderni di Diritto Ecclesiale 1 (1999) 58-69.

VIANA, A., Obispos titulares: elementos de tradición canónica y regulación actual, Ius Canonicum 88 (2004) 515-537.

—, Organización del gobierno en la Iglesia, Eunsa, Pamplona 2010.

—, La comprobación de la idoneidad para el oficio eclesiástico y el orden sagrado, Ius Ecclesiae 28 (2016) 345-366.

VILlar, J. R., Ministerio episcopal y laicado, en S. Del CuRa Elena (ed.), El ministerio episcopal, Imprenta Santos, Burgos 2001, 177-223.

VISIOLI, M., La comunione ecclesiale: rilievi canonistici, en GRUPPO ITALIANO DOCENTI DI DIRITTO CANONICO (ed.), La comunione nella vita della Chiesa: le prospettive emergenti dal Vaticano II, Glossa, Milano 2014, 35-56.

WernZ, F. X. - VidAL, P., De personis (Ius canonicum, vol. II), Universitatis Gregorianae, Romae 1943.

WIJLENS, M., Bishops and their relationship to a local Church: a canonical perspective, The Jurist 66 (2006) 211-241. 
